$41(3) \mid 2012$

Recomposiciones territoriales de las periferias de las metrópolis andinas

\title{
La sostenibilidad hídrica de la dispersión urbana en los Andes centrales colombianos: el caso del eje cafetero
}

Approvisionnement en eau et développement durable de l'étalement urbain dans les Andes centrales colombiennes: le cas de la ceinture du café

Water sustainability of urban sprawl in the central Andes in Colombia: the case

of Colombian coffee

Juan Leonardo González Plazas

\section{(2) OpenEdition}

Journals

Edición electrónica

URL: http://journals.openedition.org/bifea/464

DOI: $10.4000 /$ bifea.464

ISSN: 2076-5827

Editor

Institut Français d'Études Andines

Edición impresa

Fecha de publicación: 31 diciembre 2012

Paginación: 573-605

ISSN: 0303-7495

Referencia electrónica

Juan Leonardo González Plazas, « La sostenibilidad hídrica de la dispersión urbana en los Andes

centrales colombianos: el caso del eje cafetero », Bulletin de l'Institut français d'études andines [En línea], 41 (3) | 2012, Publicado el 01 agosto 2013, consultado el 05 noviembre 2020. URL : http:// journals.openedition.org/bifea/464; DOI : https://doi.org/10.4000/bifea.464

Les contenus du Bulletin de l'Institut français d'études andines sont mis à disposition selon les termes de la licence Creative Commons Attribution - Pas d'Utilisation Commerciale - Pas de Modification 4.0 International. 


\title{
La sostenibilidad hídrica de la dispersión urbana en los Andes centrales colombianos: el caso del eje cafetero
}

\author{
Juan Leonardo González Plazas*
}

\begin{abstract}
Resumen
Este artículo presenta una caracterización del estado de la oferta hídrica en el contexto de dispersión urbana en el eje cafetero colombiano. El autor propone que el uso del suelo en las áreas de dispersión urbana y en los entornos donde se localizan los ecosistemas que sustentan el abasto hídrico, así como la eficiencia técnico operacional de las empresas de servicios públicos que operan allí, son factores clave para entender de manera integral la oferta hídrica local y regional. El trabajo analiza el grado de urbanización y la magnitud espacial de la dispersión urbana en los municipios de Manizales, Pereira y Armenia. Luego, caracteriza el estado ecológico-social del uso del suelo en los ecosistemas andinos y subandinos que abastecen los acueductos integrados a la dispersión urbana. Por último, analiza las condiciones técnicas y operacionales de los prestadores del servicio de acueducto involucrados en la dispersión urbana, resaltando sus fortalezas y debilidades.
\end{abstract}

Palabras clave: dispersión urbana, oferta hídrica, empresa de servicio público, uso del suelo, eje cafetero

\section{Approvisionnement en eau et développement durable de l'étalement urbain} dans les Andes centrales colombiennes : le cas de la ceinture du café

\section{Résumé}

Cet article présente l'état de l'approvisionnement en eau dans le contexte de l'étalement urbain dans la région colombienne de la ceinture du café. L'usage des sols dans les zones d'étalement urbain et

* Geógrafo, Universidad Nacional de Colombia, Magister en Hábitat, Universidad Nacional de Colombia, especialista en Manejo y Gestión del Agua, Universidad de Antioquia. E-mail: juangonzalez38@gmail.com 
dans leurs environs où se localisent les écosystèmes riches en ressources hydriques, de même que l'efficacité technique et opérationnelle des entreprises de service public sont des facteurs clés pour comprendre de manière intégrale l'approvisionnement en eau, au niveau local et régional. L'article analyse le degré d'urbanisation et l'étendue spatiale de l'étalement urbain dans les villes de Manizales, Pereira et Armenia. Puis, il caractérise l'usage social et écologique des sols dans les écosystèmes andins et subandins qui approvisionnent en eau les systèmes d'aqueduc des zones de dispersion urbaine. Enfin, il analyse les conditions techniques et opérationnelles des services d'approvisionnement en eau présents dans les zones de dispersion urbaine, en soulignant leurs forces et leurs faiblesses.

Mots clés : dispersion urbaine, approvisionnement en eau, entreprises de service public, usage des sols, ceinture du café

\title{
Water sustainability of urban sprawl in the central Andes in Colombia: the case of Colombian coffee
}

\begin{abstract}
The article presents a characterization of the status of the water supply in the context of urban sprawl in the Colombian coffee region. The author suggests three factors to understand the local and regional water supply system: 1) Driving within areas of urban sprawl, 2) Land use in the ecosystems that sustain the water supply and 3) Operation and technical efficiency of the utilities. Accordingly, the work provides an estimate of the degree of urbanization and the spatial extent of urban sprawl in the cities of Manizales, Pereira y Armenia. Then, the author characterizes the ecology of land use in Andean and sub Andean ecosystems that supply the conditions and aqueducts of these cities. Finally, the study characterizes the operative and technical conditions of water supply service providers involved in urban sprawl, highlighting their strengths and weaknesses.
\end{abstract}

Key words: Urban sprawl, Water supply, Public Service Company, Land Use, Eco Coffee Town

\section{INTRODUCCIÓN}

Los Andes centrales colombianos ofrecen una variedad de escenarios fisiográficos, vertientes y piedemontes sobre los cuales se han dispuesto varios procesos de poblamiento y desarrollo de estructuras agrarias desde los últimos 200 años. En la actualidad, el hábitat de ese campesinado cafetero, que adquirió sus tierras a partir de colonizaciones dirigidas y espontáneas desde 1850 está cambiando. Abandona la producción de café para dar paso a la parcelación, cambiando el uso del suelo para la inserción de procesos urbanos dispersos en la montaña, una montaña periurbana carente de espacios públicos, de cohesiones sociales y atomizados en la forma de acceder o proyectar infraestructuras de servicios públicos. Lo anterior es una generalidad social en las veredas por las que transcurre la autopista del café y para aquellas que limitan con los cascos urbanos de ciudades y pueblos en el eje cafetero en Colombia.

Como resultado del cambio del uso del suelo, se observan escenarios con problemas de gobernabilidad, gestión urbana, vulnerables a la producción de riesgo, que 
experimentan segregaciones residenciales y donde se alteran el conocimiento de la protección de los bosques. El resultado final es un fenómeno donde la dispersión de elementos y acciones urbanas amplifica una huella ecológica-social en toda la vertiente y pone al límite los equilibrios de las estructuras ecológicas principales.

Los sistemas urbanos en Colombia tienden a aumentar sus dimensiones espaciales, esto si se tiene en cuenta que el 9 \% del PIB nacional 1 corresponde a la producción de la actividad edificadora, un elemento importante en la generación de empleos asociados principalmente a las actividades urbanas. Este motor económico incide en la magnitud espacial de las actividades urbanas en vista que a los $120428659 \mathrm{~m}^{2}$ aprobados para licencias de construcción en la última década del siglo XX, se suman ahora 130927266 m²$^{2}$ aprobados entre los años 2000 y 20092. Tal incremento se orienta hacia la localización de nuevos proyectos de vivienda, servicios, industria y comercio fuera de los perímetros urbanos de las ciudades. Considerando lo anterior y en función de un interés por estudiar las relaciones entre sociedad y naturaleza, este fenómeno social y espacial demanda tanto el diagnóstico sobre las capacidades técnico-operativas de los sistemas de acueducto y saneamiento, como el diagnóstico sobre los cambios de uso del suelo, al igual que una mayor atención sobre la valoración ecológica y social de los ecosistemas que abastecen dichos sistemas de acueducto y que finalmente llevaría a proponer algunos factores condicionantes de la oferta hídrica.

Según el Estudio Nacional del Agua del IDEAM (2008) el Índice de Escasez Hídrica (relación porcentual entre la demanda conjunta de las actividades socioeconómicas y la oferta hídrica disponible o neta) determinó el área de estudio como nivel bajo, sobre la base de la demanda potencial de agua equivalente a $10 \%$ de la oferta hídrica neta y del consumo doméstico que permanece entre el $70 \%$ y $80 \%$ del total de la demanda hídrica. Por lo tanto, la contraloría de Armenia advierte que para el 2016

«... si no se intensifican las medidas de conservación de cuencas y tratamiento de aguas residuales, el $19 \%$ de los municipios y el $38 \%$ de la población alcanzarían en dicho año un índice de escasez superior al $20 \%$...» (Contraloría Municipal de Armenia, 2009: 27).

Este artículo estudia la tensión social, ecológica y técnica que se presenta entre la oferta hídrica y el proceso de dispersión urbana en tres municipios del eje cafetero: Manizales, Pereira y Armenia. Dicha tensión entre la dispersión urbana y la oferta hídrica local consiste en un encadenamiento de acciones como la transformación del uso del suelo, cambio que altera la resiliencia social-ambiental de los ecosistemas andinos para proveer de agua a una serie de sistemas de acueductos con deficiencias técnicas y operacionales. Estos son responsables de la cobertura en agua potable y saneamiento en los municipios que presentan índices de urbanización por encima de la media urbana regional y nacional.

1 Sector de edificaciones en Colombia (Pinto, 2009).

2 Calculo de los $\mathrm{m}^{2}$ aprobados entre 1990 y 2009 en 77 municipios colombianos, base de datos DANE (2010). 
En este estudio se estima la magnitud espacial de las áreas de dispersión urbana entre los municipios, caracterizando el estado de los ecosistemas andinos que proveen de agua a estos sistemas urbanos y evaluando el estado de la cobertura y calidad del agua potable por parte de las ESP que los abastece.

\section{CONTEXTUALIZACIÓN}

El área de estudio se concentra en los municipios que gravitan alrededor de las tres urbes principales de la ecorregión del eje cafetero colombiano: Armenia, Pereira, Manizales (ver fig. 1). En total, son 14 municipios que, dada su proximidad con las ciudades intermedias del eje cafetero, tienden a una acelerada transformación de sus actividades rurales y urbanas localmente discontinuas (proyectos residenciales campestres, lotes para propósitos comerciales, industriales y de servicios). Los municipios integrados a la dispersión urbana en el eje cafetero son: Manizales, Villamaría, Chinchiná, Palestina, Santa Rosa, Dosquebradas, La Virginia, Cartago, Armenia, Calarcá, Salento, La Tebaida, Montenegro, que conforman un área potencial de dispersión de 4892 km² denominado «Eco-Región del Eje Cafetero».

\section{LA DISPERSIÓN URBANA}

Son tres los sistemas urbanos que se extienden en el eje cafetero colombiano, Manizales, Pereira y Armenia, tres ciudades que crecen de manera interrumpida entre montañas y piedemontes sísmicos contenedores de una ecología de páramos, bosques y cafetales. Junto al desplome de la economía regional del café a finales del siglo pasado, actividad que permeaba todas las capas de esta sociedad de colonos antioqueños, boyacenses y del valle del Cauca, se suma un potente sismo superficial que en 1999 destruyó parte de la infraestructura de esta región; región que en otros tiempos tenía los mejores indicadores de calidad de vida en Colombia.

Era precisamente a principios de 2002 cuando los procesos de reconstrucción estaban culminando y los gobiernos departamentales del Quindío, Risaralda y Caldas pusieron en marcha una agenda económica y social que incentivara otras actividades para reducir la dependencia de la producción de café, levantar la economía regional e insertar definitivamente la región a la globalización. Desde este momento, la inversión de diversos capitales de multinacionales, servicios públicos, finca raíz, educación, alimentos y también del narcotráfico adquirió un espacio que se ha venido extendiendo fuera de los perímetros urbanos. Los rasgos sociales de estos nuevos espacios de producción se caracterizan por una coexistencia entre población pendular propia de la ciudad y campesinos urbanizados, amalgama que viene transformando la ruralidad cafetera tradicional en cuanto a los sentidos de pertenencia que se tenían de los bosques, los ríos y a las formas de concebir el habitar, la movilidad, el trabajo y el consumo. 


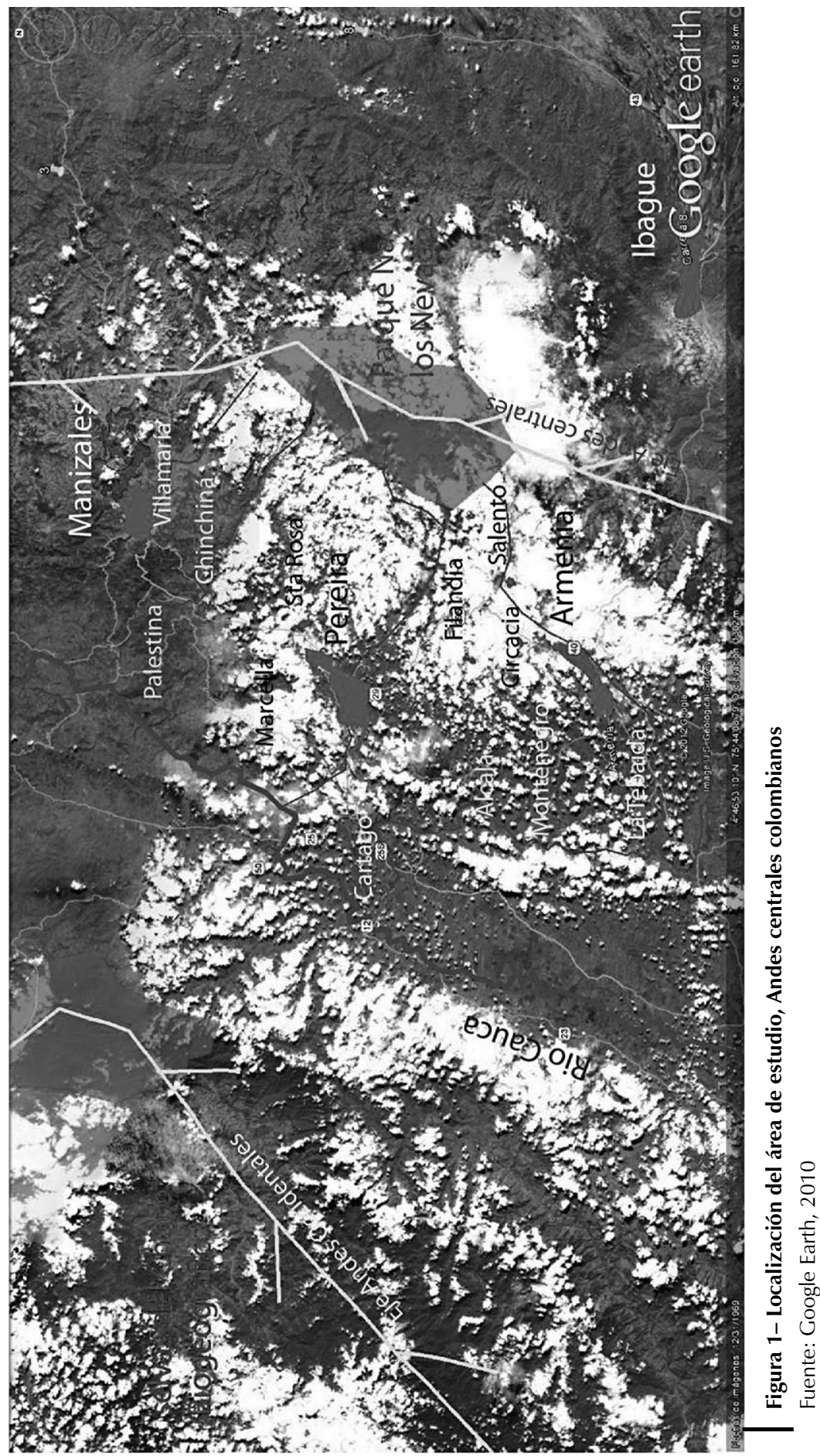


La dispersión urbana del eje cafetero es un mosaico de predios rurales, tramas urbanas fragmentadas, formas lineales, carreteras de montaña, una variedad de sistemas geotécnicos. A medida que se extiende en el paisaje cafetero genera tensiones económicas y sociales sobre el valor de uso de las fincas de producción agropecuaria. Dado que la producción local ha estado en desventaja frente a la inserción de productos venidos de otras regiones con menor precio, muchos habitantes consideraron la parcelación de su finca de producción como una opción económica siempre y cuando su predio esté dentro del sistema de vías próximo a la autopista del café, eje vial que conecta las tres ciudades.

En otro sentido, la dispersión urbana en regiones montañosas, a medida que se extiende, fomenta una fragmentación de las redes de servicios como el agua, una segregación residencial y una ausencia de espacio público. En la medida que la residencia, la industria y la agroindustria se alejan de los cascos urbanos, estos se aproximan a los sistemas ecológicos de producción de agua, es decir, hay una tendencia en invadir y cooptar corredores ecológicos, humedales, bosques y quebradas contenedores de la oferta hídrica de la región. Por otra parte, una dispersión urbana de estas condiciones incrementa los consumos de agua en ciertas microcuencas donde los sistemas de captura, almacenamiento, conducción, distribución y vertimiento son limitados o estaban proyectados para cierto número de usuarios o predios.

Teniendo en cuenta lo anterior, al incrementarse los lotes urbanizados, la calidad de agua que se le da al usuario puede no ser la mejor y el abastecimiento puede cortarse periódicamente tras la ausencia de proyectos que garantizan la oferta local como acciones de negociación de predios para conservación, dotación, ampliación y sobre todo la ejecución de planes de contingencia precisos en caso de un fenómeno de El Niño o de La Niña.

Según Ávila (2004: 99), la dispersión urbana «es una manifestación de la reestructuración de los territorios en el contexto global». Durand (1998), citado por Allen (2001: 5), agrega que

«Las zonas periurbanas suelen compartir el territorio de más de una unidad administrativa, de municipios con vínculos débiles y en la que su participación en sectores como el transporte, agua, energía, residuos sólidos y líquidos, gestión y planificación del uso del suelo es limitado a menudo, dando así lugar a la incertidumbre en cuanto a qué institución es la que administra cada uno de los sectores mencionados».

De acuerdo con lo anterior, la dispersión urbana o periurbanización es un producto social derivado de la localización de la producción económica. Es un fenómeno que potencia una nueva ruralidad, otra forma de concebir espacio público y de consumir suelo para habitar, en las formas de ocupación, en la tenencia de la tierra y en la relación entre el habitante y la naturaleza. En otros aspectos, Allen (2001: 7) expresa que

«la composición social de los sistemas periurbanos es muy heterogénea y sujeta a cambios significativos a través del tiempo. Agricultores, pobladores 
informales, empresarios industriales y residentes de ingresos altos y medios suelen coexistir en el mismo territorio, pero con intereses, prácticas y percepciones diferentes que, a menudo, compiten entre sí».

En los últimos 20 años, la producción de estudios sobre dispersión urbana ha hecho hincapié en el tema del riesgo físico asociado a las inundaciones y los deslizamientos. En otros casos, varios estudios del hábitat en la periferia están siendo orientados al tema de la familia, relaciones comunitarias, violencia, problemas por el acceso al agua, condición alimentaria y sistemas constructivos precarios. En este sentido sobresalen los trabajos realizados por la CEPAL y el BID, con una profunda visión del tema del hábitat desde el funcionamiento económico. Aquí se destacan los trabajos de Katzman (2001) sobre la segregación económica y espacial en las periferias urbanas, Blaikie et al. (1996) sobre los eventos peligrosos y su manifestación en las periferias urbanas y de Durán (2004) sobre las definiciones y diferenciación de los escenarios periurbanos igualmente definidos para suramérica por Barros (1999: 10). Este último define dos escenarios o periferias que constituyen el interfaz urbano rural:

- un primer escenario periurbano influenciado directamente por la proximidad del núcleo urbano principal en el cual es evidente la expansión acelerada de la red urbana;

- un segundo escenario periurbano caracterizado por la permanencia de la ruralidad, su función como cuenca próxima de abastecimiento energético (alimentos, materia prima), bajo un control administrativo del núcleo urbano principal, articulado por una red (carreteras) de conexión compuesta por nodos (cabeceras municipales) integradas a un nodo principal e influenciadas por otros nodos (ciudades).

A nivel global, en la actualidad los estudios sobre dispersión urbana se orientan hacia una interpretación teórica con base en las dinámicas políticas y económicas de la globalización y su manifestación espacial en la periferia. Sobresalen la producción de Tacoli (1998) acerca de los vínculos económicos urbanos y rurales en la periferia y de Pedersen (2003) sobre las dicotomías entre las acciones político administrativas en el tema de la descentralización; investigación que explican en parte la naturaleza de la problemática de la periferia urbana resultante de la pluralidad de visiones del desarrollo espacial entre los mundos rural y urbano.

En busca de alternativas conceptuales y metodológicas para estudiar la dinámica de los procesos de conectividad ecológica, tecnológica, de servicios y de comunicación desarrollados al interior de sistemas urbanos dispersos, se ha propuesto la inclusión de disciplinas como la ecología humana, la física y la geografía y la referencia a paradigmas como los objetos fractales y la holística. El trabajo de Bettini (1998) compila una serie de tendencias de estudios experimentales en hábitat periurbano a partir de elementos de análisis sistémico metabólico que consideran el sistema urbano como un organismo. 


\section{LA OFERTA HÍDRICA EN EL MARCO DE LA DISPERSIÓN URBANA}

A medida que los sistemas urbanos se dispersan abarcando diferentes municipios e incidiendo sobre el cambio del uso rural al urbano, la demanda de cobertura para dotación en agua y saneamiento básico urbano se vuelve compleja. Esta complejidad se concentra en tres sentidos:

1) Un incremento de la demanda de agua soportada por ecosistemas que de por sí presentan alteraciones en su capacidad de producción y de calidad del agua antes de ingresar al sistema de acueducto, potabilización y conducción debido a la presión ecológica que se presenta en sus alrededores (fronteras agrícolas y deforestaciones).

2) La aproximación de elementos urbanos cerca o en medio de estructuras ecológicas, aspecto que afecta la capacidad hídrica de nacimientos y cursos de quebradas que hacen parte de sistemas de abastecimiento hídrico propias del lugar o externas a este.

3) La demanda económica-social por ampliar las redes para las coberturas de agua y saneamiento, administradas por una serie de ESP grandes y pequeñas, las cuales, manifiestan problemas de orden técnico en cuanto a la ampliación, la conducción, el suministro y el monitoreo de sus redes.

Para atender la demanda y complejidad espacial de la dispersión urbana es necesario no solo conocer el estado de la oferta que se formula conociendo el ciclo hidrológico (precipitación, escorrentía, evapotranspiración, influencia del ENSO) y la capacidad de regulación de los ecosistemas proveedores, sino también las dinámicas sociales, es decir acciones desarrolladas desde la sociedad que son determinantes para la estabilidad de los ecosistemas productores en las relaciones sociedad/naturaleza y las relaciones sociedad/espacio. De esta forma, la oferta hídrica vista desde el contexto social podría acercarse a la estimación real de la capacidad, calidad y aprovisionamiento de agua para los diferentes usos urbanos en crecimiento.

\section{LAS CONDICIONES DE ESTABILIDAD ECOLÓGICA EN LOS ECOSISTEMAS PROVEEDORES DE LOS ACUEDUCTOS}

El estudio de la estructura y función de los ecosistemas permite definir su estabilidad en tiempo y espacio. A mayor diversidad de elementos bióticos interactuantes desarrollados en los niveles de estratificación vertical del bosque y de su posibilidad de expansión horizontal, mayor estabilidad ecológica. Esta estabilidad permite un funcionamiento óptimo en los ciclos de regulación y almacenamiento de energía tanto de forma vertical (dada en la estratificación arbórea) como horizontal (en sus posibilidades del bosque de interactuar por medio de la conexión con otros bosques), aspecto que es determinante en las potencialidades hídricas del ecosistema. 
En el caso particular de este estudio, existe un interés por relacionar el estado ecológico y los aspectos que limitan la oferta hídrica de los ecosistemas andinos y subandinos de los Andes centrales colombianos. Estos remanentes establecidos entre los 1400 y 2800 m.s.n.m. presentan diferentes situaciones de alteración por parte de la intervención humana, que incide en la espacialidad y propiedades del ecosistema al punto de ser la acción fundamental que determinaría las dimensiones espaciales de los bosques andinos y subandinos.

Según Riitters (2000), citado por Armenteras \& Rodríguez (2007: 55) se han podido establecer cuatro patrones de fragmentación para los bosques andinos colombianos que permiten analizar las posibilidades de conexión, estabilidad, recuperación así como tendencias de alteración y de extinción: 1) bosque perforado, 2) bosque transicional, 3) bosque de borde y 4) bosque parche.

La definición de los patrones espaciales de fragmentación permite comprender varias situaciones. Por un lado, establece un panorama espacial de la fragmentación y con ello las oportunidades espaciales locales y regionales en la estimación de la oferta hídrica, por otro lado, permite visualizar aspectos de vulnerabilidad de los ecosistemas desarrollados principalmente por la presión de prácticas ganaderas y en menor medida por la deforestación sobre los bosques. Esto permite dimensionar las posibilidades de abastecimiento de acueducto regulado por las ESP, al conocer las particularidades espaciales de los bosques proveedores de agua, así como de la creación de mecanismos de protección y de recuperación de masas de bosque en lugares críticos por parte de las ESP y los municipios.

\section{LA EFICIENCIA DE LAS EMPRESAS DE SERVICIOS PÚBLICOS (ESP)}

Una ESP se define como una entidad de orden mixta, privada o pública encargada de gestionar, administrar y dotar el sistema de abastecimiento hídrico y de saneamiento en contextos rurales y urbanos. De manera que su rol en la oferta hídrica es de orden tecnológico y social. Al igual que los instrumentos de clasificación de los usos del suelo dados en la planificación, las ESP son estructuras sociales de mediación entre un recurso como el agua, su calidad para el consumo y el acceso que pueda tener la población y los procesos productivos. En esta medida una ESP puede actuar en un territorio como agente de control al acceso al agua y su red tiende a ampliarse en lugares donde la especulación por el precio del suelo cambia un lote agrícola o de conservación por una empresa o un condominio.

En Colombia, según el Sistema Único de Información (SUI) adscrito a la Superintendencia de Servicios Públicos Domiciliarios (SSPD) y a la CRA existen 1282 ESP de pequeña escala (hasta 2500 usuarios) y 224 ESP de mayor escala (más de 2500 usuarios). De las 1507 ESP registradas solo 137 presentan hasta el año 2009 informe de gestión ante la Superintendencia de Servicios Públicos. Esto quiere decir que en el momento, el gobierno nacional no cuenta con datos concretos sobre el estado financiero y técnico de las ESP en diversos lugares del país. A este vacío de información se suma una serie de asociaciones de usuarios y 
/ o corporaciones de niveles locales-veredales no reportadas ante la SUI. Según la liga de usuarios de servicios públicos existirían alrededor de 11000 asociaciones que regulan los acueductos veredales en el país, sin que existan datos oficiales sobre su estado de operación.

Las condiciones financieras, administrativas y técnicas de las ESP son factores importantes en la regulación de la oferta hídrica. Su gestión es la que permite realmente el acceso al agua potable y en un contexto de dispersión urbana su papel tiene que ver con las posibilidades presupuestales, de subsidios, tecnológicas y de cierres financieros con las cuales cuenta la ESP para atender el incremento de las demandas dada por las nuevas localizaciones residenciales, industriales, de servicios y comerciales. La eficiencia de las ESP pequeñas y de gran escala depende de las capacidades de organización que ellas tengan, estableciendo proyecciones acerca de su futura cobertura, aspecto que depende de la previsión financiera que subyace en el cálculo de los costos medios de inversión (CMI) y en la cual están proyectadan dentro del valor presente neto (VPN) las inversiones actuales para cinco años.

Una variable determinante en la oferta hídrica es la Clasificación del riesgo financiero (IFA) de la ESP ante la SSPD, el cual se construye sobre varios criterios: (a) la liquidez y endeudamiento de la empresa, (b) la eficiencia en el recaudo, (c) la cobertura de intereses y (d) la clasificación del riesgo operativo. El IFA además tiene en cuenta el cumplimiento de los índices de Riesgo de Calidad del Agua definidos por el Índice de riesgo para consumo humano (IRCA) y la verificación sobre la aplicación de la reglamentación de la CRA, sustentada bajo los parámetros de la reglamentación en agua y saneamiento (RAS 2010).

Lo anterior se constituye como una variable fundamental en el análisis de la oferta hídrica ya que se requiere de sistemas administrativos eficientes y sostenibles que garanticen el abastecimiento hídrico y el saneamiento en el municipio donde es evidente el crecimiento urbano. Lamentablemente, aspectos como el vacío de información, la atomización de sistemas de acueductos y las autonomías en los mecanismos de administración, tanto de las ESP como las asociaciones, no permite en el momento un panorama claro de los gobiernos departamentales y municipales sobre las capacidades de cada ESP para sostener una cobertura urbana dispersa. Es importante, conocer la resiliencia local-regional de un sistema de acueducto y alcantarillado ante eventos extremos como los fenómenos de El Niño y La Niña y sobre todo, conocer las capacidades de cada ESP para prestar una cobertura a un área de dispersión urbana.

\section{METODOLOGÍA DEL ESTUDIO}

La propuesta metodológica se realizó en tres etapas. 1) Hacer la revisión bibliográfica para establecer el grado de urbanización de cada municipio estudiado, identificar las cuencas hidrográficas abastecedoras de los sistemas urbanos y determinar las ESP que operan en cada uno de estos. 2) Un trabajo de campo realizado entre 2007 y 2009 en el eje cafetero y la participación en distintas actividades 
de los comités técnicos de la ecorregión eje cafetero3. 3) Revisión de los informes de Gestión de las ESP que operan en las áreas de estudio, para evaluar sus condiciones técnico-operacionales, destacando sus fortalezas y debilidades frente a la cobertura de las necesidades urbanas en crecimiento. En el trabajo de campo se hicieron levantamientos de unidades de paisaje (caracterización biofísica y del usos del suelo) y la georeferenciación de las áreas donde se presentan cambios en el uso del suelo con presencia de elementos urbanos en contextos rurales de los municipios estudiados, lo que permitió definir una magnitud espacial aproximada del área de dispersión urbana.

De igual forma, se identificaron los ecosistemas andinos y subandinos comprometidos con la oferta y se identificaron los problemas ecológicos y sociales que alteran su funcionamiento. Al mismo tiempo, se realizó una generalización de los usos del suelo involucrados en las áreas de dispersión urbana y en los alrededores de los ecosistemas con el fin de establecer conflictos de uso generalizados a escala 1:100.000. Para ello, se utilizó la nomenclatura del modelo de coberturas terrestres CORINE LAND COVER4.

Por último, se desarrolló una cartografía temática soportada en el trabajo de campo, los polígonos georeferenciados, la interpretación de coberturas por medio de Google Earth Pro verificadas en campo y el diseño final en el programa llustrator CS4 con el fin de especializar las complejidades de las relaciones de dispersión urbana y oferta hídrica. Esta cartografía expone una síntesis de las condiciones biofísicas, la generalización de los usos del suelo, la magnitud espacial de la dispersión urbana y la identificación de pequeños subcentros en crecimiento.

\section{LA EXPANSIÓN DE LOS SISTEMAS URBANOS EN EL EJE CAFETERO}

La ecorregión eje cafetero se denomina así por la estructura de cuencas hidrográficas que tienen su origen en el complejo glaciar-volcánico de páramos y selvas andinas conocido como el complejo Ruiz Tolimas. En este y a lo largo de la vertiente occidental de la cordillera central se forman relieves asociados a piedemontes y unidades montañosas entre los 900 y 5000 m.s.n.m., donde se estructuran las cuencas hidrográficas de los ríos Chinchiná, Otún y La Vieja, las cuales hacen parte de la cuenca sedimentaria del río Cauca. En la vertiente de estudio se han

3 Formulación y acompañamiento a las mesas técnicas del Hábitat en la ecorregión eje cafetero, abril 2005, la Tebaida, Quindío Universidad de Caldas, Alma Mater, Corporación Autónoma del Quindío, Universidad Autónoma de Manizales, Universidad Gran Colombia. Quindío.

4 Base de datos sobre la cobertura y uso del territorio en la Unión Europea dirigido por la Agencia Europea de Medio Ambiente (AEMA).

5 El estudio de ECOSISTEMAS TROPO ANDINOS de 1995 adoptó este concepto para definir el contexto espacial del eje volcánico y de sistemas glaciares residuales con altitudes entre 3000 y 5200 m.s.n.m localizado en los departamentos de Caldas, Tolima, Risaralda y Quindío. Esto integra en su contexto un sistemas de páramos en los cuales se originan las cuencas hidrográficas de los ríos Chinchiná, río Claro, Otún y Quindío hacia la vertiente occidental de los Andes centrales colombianos. 
establecido diferentes verticalidades de producción agraria (ganaderías, café, caña, forestal) con ecosistemas de páramo, andino y subandino que garantizan los procesos ecológicos entre el eje de la cordillera y la depresión del río Cauca. En términos geomorfológicos, los escenarios de descripción se localizan en las unidades morfogénicas andinas de media montaña (1 200-2 900 m.s.n.m.) y baja montaña (500-1 200 m.s.n.m.)6.

El área de estudio expone diferentes recursos hídricos pertenecientes a las cuencas mencionadas utilizadas para el abastecimiento de los sistemas urbanos a estudiar. Según esta clasificación, existen 27 subcuencas registradas por los informes de gestión de las ESP y de las autoridades ambientales regionales Corpocaldas, Carder, CVC y CRQ, en las cuales se concentran las captaciones iniciales para cada municipio. Los 14 municipios que integran el proceso de dispersión urbana en el eje cafetero suman un área de 4324 km². El área urbana consolidada entre todos es de $165,77 \mathrm{~km}^{2}$ y el área potencial de dispersión urbana conjunta es de $243,71 \mathrm{~km}^{2}$. Este último se define a partir de las actividades rurales en transformación a raíz de la implementación de usos del suelo urbanos: residenciales, de servicios, industriales y comerciales.

El cuadro 1 expone otros datos a tener en cuenta. Por un lado se determina que el área de dispersión urbana propuesta en este estudio, áreas estimadas a partir del reconocimiento de escenarios rurales con presencia de actividades urbanas en campo (fotos interpretadas en Google Earth y cuantificadas por medio del aplicativo earthpoint.us) resulta superior a las áreas urbanas consolidadas, siendo la expansión urbana de Pereira la más importante con 86,66 km² de área consolidada frente a 90,52 km² de área de dispersión, seguido por Armenia con 29,07 km² y 82,14 km² de dispersión y por último el Manizales con 50,04km² y $71,05 \mathrm{~km}^{2}$ de dispersión.

Respectivamente, la relación (magnitud espacial) acorde con los datos del grado de urbanización promedio en cada sistema urbano presenta Pereira como el más alto (con $91 \%$ ), seguido de Armenia con (79 \%) y Manizales con (73\%), para un promedio regional de urbanización del 81 \% (ver fig. 2). Tanto el área potencial de dispersión como el grado de urbanización responden a la magnitud del proceso de urbanización en la región y su intensificación en los municipios involucrados y entre estos, situación que genera una mayor demanda de la cobertura y calidad de los acueductos actuales y futuros.

La proyección espacial de la dispersión urbana en el eje cafetero está estructurada sobre tres núcleos urbanos principales, los cuales inciden en cada uno de los municipios satelitales dadas su proximidad y su articulación a la autopista del café. Estos escenarios concentran condiciones propicias para la transformación del uso del suelo rural al urbano, aspecto significativo en la evaluación del estado de la oferta hídrica en sus aspectos de cobertura, calidad y conflictos ecológicos. Cada núcleo urbano desarrolla un sistema urbano-periurbano que se define a continuación.

6 Referidos a unidades de relieve o modelado reconocidos en escalas cartográficas medias 1:200.0001:100.000 (Florez, 2003: 257). 
La sostenibilidad hídrica de la dispersión urbana en los Andes centrales colombianos: el eje cafetero

Cuadro 1 - Áreas, población y grado de urbanización de los municipios estudiados Juan Leonardo González, tomado de bases de datos DANE 2012

\begin{tabular}{|c|c|c|c|c|c|c|c|}
\hline $\begin{array}{l}\text { Sistema } \\
\text { urbano-peri } \\
\text { urbano }\end{array}$ & Municipio & $\begin{array}{l}\text { Área } \\
\text { total } \\
\left(\mathbf{k m}^{2}\right) \\
\end{array}$ & $\begin{array}{l}\text { Área } \\
\text { urbana }\end{array}$ & $\begin{array}{l}\text { Área de } \\
\text { dispersión } \\
\text { urbana }\end{array}$ & $\begin{array}{l}\text { Población } \\
\text { total }\end{array}$ & $\begin{array}{l}\text { Población } \\
\text { urbana }\end{array}$ & $\begin{array}{l}\text { Población } \\
\text { rural }\end{array}$ \\
\hline & Manizales & 508 & 45 & 60,2 & 368433 & 342620 & 25813 \\
\hline \multirow{3}{*}{ MANIZALES } & Villamaría & 461 & 2,1 & 1,48 & 45038 & 35772 & 9266 \\
\hline & Chinchiná & 112,4 & 2,64 & 5,59 & 51301 & 43448 & 7853 \\
\hline & Palestina & 108,7 & 0,3 & 3,78 & 17130 & 5628 & 11682 \\
\hline \multirow[t]{3}{*}{ subtotal } & & 1190,1 & 50,04 & 71,05 & 481902 & 427468 & 54614 \\
\hline & Santa Rosa & 1701 & 3,46 & 0,36 & 67410 & 54407 & 13003 \\
\hline & $\begin{array}{l}\text { Dos } \\
\text { Quebradas }\end{array}$ & 70 & 20,2 & 6 & 173452 & 164437 & 9015 \\
\hline \multirow[t]{3}{*}{ PEREIRA } & Pereira & 97 & 46,1 & 80,02 & 428397 & 358681 & 69716 \\
\hline & La Virginia & 33 & 1,7 & 3,21 & 30095 & 29546 & 549 \\
\hline & Cartago & 279 & 15,2 & 0,93 & 121741 & 119063 & 2678 \\
\hline \multirow[t]{3}{*}{ subtotal } & & 2180 & 86,66 & 90,52 & 821095 & 726134 & 94961 \\
\hline & Salento & 375 & 0,8 & 0,85 & 7001 & 3494 & 3507 \\
\hline & Armenia & 121,33 & 22,53 & 31,5 & 272574 & 265020 & 7554 \\
\hline \multirow[t]{3}{*}{ ARMENIA } & Calarcá & 219,23 & 2,44 & 0,91 & 71605 & 54639 & 16966 \\
\hline & Montenegro & 148,92 & 1,8 & 8,91 & 38714 & 31252 & 7462 \\
\hline & La Tebaida & 89,18 & 1,5 & 39,97 & 32748 & 29955 & 2793 \\
\hline subtotal & & 953,66 & 29,07 & 82,14 & 422642 & 384360 & 38282 \\
\hline TOTALES & & 4,324 & 165,77 & 243,71 & 1725639 & 1537962 & 187857 \\
\hline
\end{tabular}

El primero corresponde a los espacios de transformación rural-urbana reconocidos en trabajo de campo, estructurados por la autopista del café, la vía ManizalesMedellín y la vía Manizales-Bogotá y que agrupan sectores de los municipios de Manizales, Villa María, Chinchiná y Palestina. Como generalidades de esta área, la construcción del aeropuerto regional en Palestina es un factor que ha incidido en la transición de usos cafeteros a usos residenciales y de servicios principalmente, agregando los desarrollos residenciales y turísticos hacia el sector de la Santa Águeda, la localización de instalaciones industriales, de comercio y servicios entre Villamaría y Manizales, el surgimiento de parcelaciones para usos residenciales en veredas cafeteras de Manizales y la continuidad de proyectos de este mismo orden de forma aislada entre Villamaría y Manizales como producto de la escasez de suelo urbano que vive esta ciudad.

El segundo escenario periurbano se proyecta desde Pereira hacia Dosquebradas y Santa Rosa de Cabal, de Pereira hacia la Virginia, Cartago y Alcalá y de Pereira hacia el sur por la autopista del café hacia Armenia. En cada uno de estos se han reconocido nuevos subcentros residenciales, industriales, de servicios y comerciales como Combia, Cerritos, El Tigre y Morelia. En cada uno de estos frentes de urbanización se da una diversidad de mercados de suelo específicos. En el sector de El Tigre, Cerritos y Córcega la tendencia está inclinada a la vivienda campestre, mientras que en sectores como Combla en la vía perimetral Dosquebradas- 
Juan Leonardo González Plazas

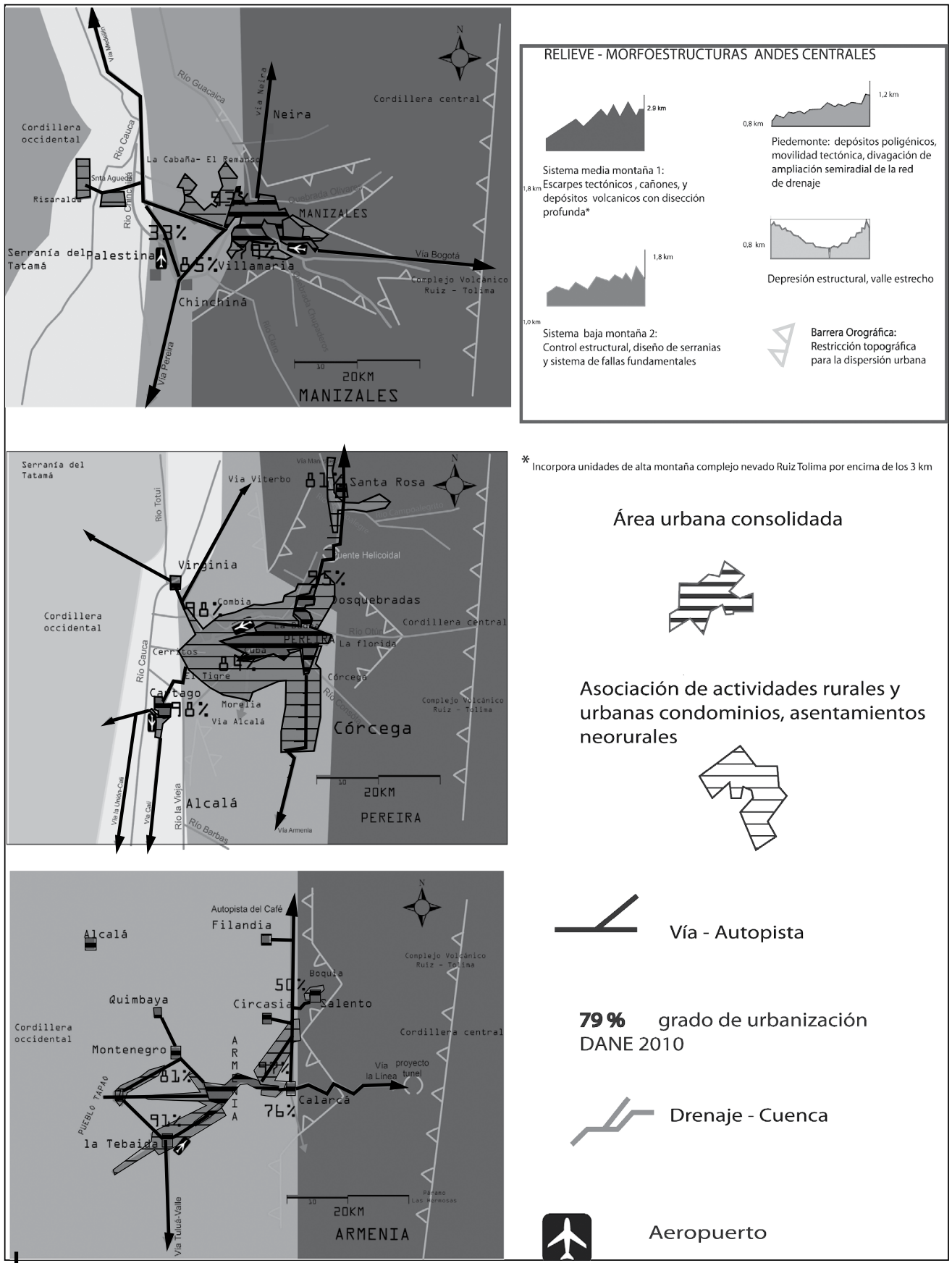

Figura 2 - Localización de los sistemas urbanos, áreas de dispersión urbana y grado de urbanización en el eje cafetero

Juan Leonardo González 
Cartago, la tendencia se inclina hacia el desarrollo de instalaciones industriales y de servicios asociados y desarrollos residenciales barriales, potenciados por las actividades económicas dadas en esta vía.

El tercer escenario se proyecta desde la ciudad de Armenia hacia el municipio de Salento al norte y hacia los municipios de Montenegro y la Tebaida al occidente y al suroriente por la vía Bogotá hacia el municipio de Calarcá. Este sistema se caracteriza por desarrollos residenciales y turísticos principalmente promovidos por los planes de desarrollo de los municipios, identificando el sector de Pueblo Tapao y sus conexiones hacia los cascos urbanos de la Tebaida, Armenia y Montenegro.

Considerando lo anterior, son 14 los planes de ordenamiento territorial que tienen bajo su responsabilidad la proyección de los recursos, las infraestructuras y el uso del suelo frente al hecho de la inserción de elementos y dinámicas urbanas en las ruralidades de estos municipios y que trabajan de la mano con las autoridades ambientales y los planes de desarrollo departamentales. El problema que surge al momento de ordenar los espacios de producción y conservación radica en la presión que ejerce cada consejo municipal para modificar los usos programados por las oficinas de planeación en procura de habilitar espacios rurales que permitan el desarrollo de nuevas actividades urbanas. De igual forma, las licencias ambientales, certificados dados por las autoridades ambientales para poder ampliar las dotaciones industriales, comerciales y de servicios, pueden variar en su concepto de restricción y/o prohibición de acuerdo a los intereses regionales y la presión política que ejercen los gremios de la producción económica local.

Por lo tanto, es factible encontrar en estos municipios normas y zonificaciones que solo operan en el papel, susceptibles de ser modificadas y donde la administración no expone de manera clara las proyecciones poblacionales tendenciales a futuro en las veredas, así como acciones conjuntas entre municipios para el desarrollo de planes maestros de acueductos y alcantarillado.

En consecuencia, en un contexto de crisis cafetera, la necesidad de habilitar áreas urbanas encuentra en los predios cafeteros y su parcelación una oferta de suelo para propósitos residenciales y que a la vez se convierte en una salida económica del habitante próximo a municipios como Manizales, Armenia, Calarcá, La Tebaida y Montenegro entre otros.

La parcelación para propósitos residenciales, dispersos en los casos de Manizales y Armenia, pone al límite las capacidades de sus acueductos veredales en vista de que el cambio del uso del suelo afecta las coberturas arbóreas subandinas y andinas que sustentan la oferta hídrica de las mismas captaciones, al igual que incrementan los niveles de vertimiento sobre estas`.

7 La contraloría de Armenia confirmó el deterioro de todos los cuerpos hídricos superficiales de la región. «... El deterioro hace referencia a olores molestos en el 80 \% del área urbana y riesgo sanitario por contaminación de las quebradas y cañadas, impidiendo cualquier uso de tipo recreativo de las quebradas...» (Contraloría de Armenia, 2009: 30). Igualmente sostiene que los sectores rurales que se abastecen de las quebradas, son afectados por su limitado uso debido a la contaminación, 
Según el Plan General Estratégico y de Inversiones del departamento de Caldas (PDA Caldas, 2008: 60), los escenarios donde se disponen los nuevos proyectos inmobiliarios presentan una contaminación periódica por aguas mieles de café en época de cosecha, a la que se le agregan los nuevos vertimientos de los asentamientos. Dado que son corrientes de ladera con fuerte pendiente, en sitios como La Cabaña y El Remanso en Manizales se presentan problemas de torrencialidad, de aumento de turbidez, con la consecuencia de destrucción o acumulación de sedimentos en las bocatomas; razones suficientes para que los acueductos mantengan racionamientos en época de sequía y de suspensión temporal del servicio de agua en épocas invernales (PDA Caldas, 2008: 60).

Un caso similar ocurre entre Armenia y la Tebaida, Armenia Montenegro y Pueblo Tapao, escenarios donde se han generado nuevos espacios urbanos y en los que la cobertura de acueductos existentes depende tradicionalmente de cuencas muy susceptibles a los periodos secos en el caso de las cuencas del río Quindío y el río Espejo. Ante esta situación, se asume que la alta temporada turística, la cual coincide con el período seco de enero, hace que los sistemas de acueductos locales presenten problemas no solo en su cobertura sino en su calidad.

En el caso del sistema urbano proyectado desde Pereira hacia sectores como Combia, El Tigre, Cerritos y Tribunas se presentan diferentes situaciones a tener en cuenta. En el sector de Combia, donde se concentran diferentes asociaciones de acueductos, el periodo seco de enero a marzo disminuye la capacidad de los afluentes. En El Tigre y Cerritos8, se proyecta una fuerte oferta inmobiliaria residencial de casas campestres con dependencia de la compra de agua en bloque procedente de la ESP de Pereira y en la que el mismo proceso de urbanización satura la capacidad de suministro de los acueductos locales, previendo a futuro opciones de captaciones subterráneas o la dependencia absoluta de la provisión de agua procedente de otros sectores, aspecto que podría incrementar con el tiempo el precio del agua gravado en las facturas9. El sector de Tribunas-Córcega presenta una tipología de viviendas similar al caso de Cerritos y El Tigre. Allí operan varias asociaciones de acueductos veredales altamente vulnerables en sus

presentando un riesgo potencial medio-alto a la salud de la población adyacente a las fuentes de agua y las ubicadas aguas debajo de los sitios de descarga (Contraloría de Armenia, 2009: 35). Contraloría Municipal de Armenia, año 2009 Estado de los Recursos Naturales, Vigencia 2008.

8 La Carder, a través de diferentes campañas de campo, ha inventariado aproximadamente 140 pozos profundos y 540 aljibes en el Municipio, donde la mayor densidad de captaciones de agua subterránea se localizan en Cerritos (Agudelo \& Orozco, 2009: 56).

9 Agua en bloque para Cerritos-Chapinero. La Empresa de Acueducto y Alcantarillado de Pereira S.A. E.S.P, presta el servicio de acueducto a un total de 3314 suscriptores (aproximadamente a 16570 usuarios), que corresponde al 22,7 \% de la población rural total, y al 24,6 \% del total de usuarios del servicio de acueducto de los Corregimientos de Caimalito, Cerritos y Puerto Caldas, los cuales cuentan con agua potabilizada permanentemente. Adicionalmente, la empresa vende agua potable en bloque a la Asociación de Usuarios del Acueducto de Cerritos-Chapinero. Los suscriptores del servicio de suministro de agua para consumo humano del centro poblado del Corregimiento de Caimalito, cuentan con el servicio de sus acueductos comunitarios (Caimalito I y Caimalito II) y de la Empresa de Acueducto y Alcantarillado de Pereira S.A. E.S.P. (Agudelo \& Orozco, 2009: 63). 
áreas de captación por parte de la presión ecológica ejercida por las actividades de ganadería en las cuencas altas de los ríos Barbas y Consota.

Por último, en municipios como Santa Rosa y Salento actualmente se desarrollan las actividades turísticas y los espacios residenciales (iresidencias principales y secundarias?). De un tiempo atrás la parcelación sobre unidades agroproductivas al margen del río Quindío (sector de Boquía-Salento, San Juan de Carolina) y la cuenca del río Campo alegrito entre Santa Rosa y el sector de Termales, ha incrementado la presión ecológica, por contaminación y densificación poblacional. A partir de esto, las unidades ecoturísticas desarrolladas en el valle del Cocora amenazan los estados de aislamiento de los bordes de ecosistemas que interconectan páramos y selvas andinas-subandinas en la cuenca alta del río Quindío.

Ante este panorama de crecimiento urbano y para organizar y proyectar a futuro las infraestructuras de agua y saneamiento, se contrató un equipo consultor para evaluar la calidad de la cobertura en agua potable y saneamiento en los 3 departamentos. Como resultado se elaboraron una serie de informes radicados como fases de diagnóstico de los PDA10 en cada una de las regiones informando el estado mediante balances financieros proyectados a corto, mediano y largo plazo sobre inversiones en obras de optimización, rehabilitación y ampliación de capacidad hidráulica de los sistemas de acueductos urbanos y rurales enfocados a mejorar la continuidad del servicio11.

\section{LA CONDICIÓN DE LOS ECOSISTEMAS PROVEEDORES DE LOS ACUEDUCTOS}

La mayoría de microcuencas abastecedoras de acueductos de las áreas de estudio tienen ecosistemas impactados por la presencia de zonas ganaderas y cafeteras, de modo que estas actividades alteran la calidad del agua que ingresa a las captaciones de los sistemas de acueducto por medio del aporte de los vertimientos de aguas residuales domésticas y agropecuarias12, como se muestra en el cuadro 2. De acuerdo con Agudelo \& Orozco (2009), en las áreas de estudio existe:

10 El documento Conpes 3463 de marzo de 2007 propone los lineamientos para los «Planes Departamentales de Agua y Saneamiento para el Manejo Empresarial de los Servicios de Acueducto, Alcantarillado y Aseo (PDA)», en particular los principios fundamentales de estos planes, sus fases, los esquemas institucionales y financieros, y las recomendaciones para su formulación y desarrollo (PDA Quindío, 2008: 19).

11 Por medio de talleres con todas las EPS y secretarías de planeación se diseñó una matriz de fortalezas y debilidades operativas para determinar la viabilidad de cada una de estas. El análisis detallado de cada matriz, fue realizado por la Gerencia Asesora de cada PDA. En base a las debilidades encontradas se concertó, con cada una de las empresas, la elaboración de un listado de la información sobre los desconocimientos que se tenían en interpretación de la normativa vigente además de la redacción de compromisos por parte de la ESP a remitir la documentación requerida.

12 El Estudio Nacional del Agua realizado por el Ideam con proyección a 2016, señala el incremento de la demanda para los diferentes usos y reducción de la oferta. El informe de la contraloría de Armenia advierte que «... si no se intensifican las medidas de conservación de cuencas y tratamiento de aguas residuales, el $19 \%$ de los municipios y el 38 \% de la población alcanzarían en dicho año un índice de escasez superior al 20 \%...» (Contraloría Municipal de Armenia, 2009: 27) 
Cuadro 2 - Relación de cuencas, empresas de acueducto, usos del suelo y ecosistemas Juan Leonardo González, modificado de bases de datos EPS

\begin{tabular}{|c|c|c|c|c|c|}
\hline $\begin{array}{l}\text { SISTEMA URBANO- } \\
\text { PERIURBANO }\end{array}$ & MUNICIPIO & & $\begin{array}{l}\text { INDICE DE PRESION } \\
\text { (DEMANDA/OFERTA)*100000 }\end{array}$ & OPERADOR ESP & $\begin{array}{l}\text { CUENCAS DE } \\
\text { ABASTECIMIENTO }\end{array}$ \\
\hline \multirow{4}{*}{ MANIZALES } & MANIZALES & MEDIO ALTO & MUY ALTO & $\begin{array}{l}\text { AGUAS DE } \\
\text { MANIZALES }\end{array}$ & $\begin{array}{l}\text { río. Blanco } \\
\text { quebrada. Cajones } \\
\text { quebrada California } \\
\text { rio Chinchiná } \\
\text { quebrada La arenosa } \\
\text { quebrada La Maria } \\
\text { quebrada la Ye } \\
\text { quebrada Olivares } \\
\text { quebrada Pinares } \\
\text { quebrada Romerales } \\
\text { quebrada Termales }\end{array}$ \\
\hline & VILLAMARIA & MINIMO & MUY ALTO & ACUAMANA & $\begin{array}{l}\text { quebrada La Allbania } \\
\text { quebrada Chupaderos }\end{array}$ \\
\hline & CHINCHINA & NO SIGNIFICAT & MUY ALTO & EMPOCALDAS & $\begin{array}{l}\text { quebrada los Cuervos } \\
\text { Rio Campoalegre }\end{array}$ \\
\hline & PALESTINA & NO SIGNIFICAT & MUY ALTO & EMPOCALDAS & quebrada Betania \\
\hline \multirow{5}{*}{ PEREIRA } & SANTA ROSA & MEDIO & MEDIO ALTO & EMPOCABAL & $\begin{array}{l}\text { río Campoalegrito } \\
\text { río San Eugenio }\end{array}$ \\
\hline & DOSQUEBRAD & MINIMO & MEDIO ALTO & SERVICIUDAD & $\begin{array}{l}\text { Aqua en bloque } \\
\text { de Empocabal y Esp Pereira }\end{array}$ \\
\hline & PEREIRA & MEDIO ALTO & MUY ALTO & ESP PEREIRA & río Otún \\
\hline & LA VIRGINIA & MUY ALTO & MUY ALTO & ESP LA VIRGINIA & rí Totui \\
\hline & CARTAGO & MUY ALTO & MUY ALTO & EMCARTAGO & \\
\hline \multirow[t]{2}{*}{ ARMENIA } & \begin{tabular}{|l|} 
SALENTO \\
MONTENEGRO \\
ARMENIA \\
LA TEBAIDA
\end{tabular} & $\begin{array}{l}\text { MUY ALTO } \\
\text { |ALTO } \\
\text { NO SIGNIFICAT } \\
\text { MEDIO }\end{array}$ & $\begin{array}{l}\text { MEDIO BAJO } \\
\text { MEDIO ALTO } \\
\text { MEDIO ALTO } \\
\text { ALTO }\end{array}$ & EPA & rio Quindio \\
\hline & CALARCÁ & MEDIO ALTO & MEDIO BAJO & ESP CALARCA & $\begin{array}{l}\text { río Santo Domingo } \\
\text { quebrada San Rafael } \\
\text { quebrada .Naranjal } \\
\text { quebrada Salado }\end{array}$ \\
\hline
\end{tabular}


La sostenibilidad hídrica de la dispersión urbana en los Andes centrales colombianos: el eje cafetero

\begin{tabular}{|c|c|c|}
\hline $\begin{array}{l}\text { ECOSISTEMAS } \\
\text { DE ABASTEMIENTO }\end{array}$ & $\begin{array}{l}\text { CONTEXTO DE USO DEL SUELO } \\
\text { SEGUN CORINE LAND COVER }\end{array}$ & $\begin{array}{l}\text { FACTORES QUE } \\
\text { ALTERAN LA CALIDAD }\end{array}$ \\
\hline Andino & $\begin{array}{l}\text { 3.1.5.1 bosque plantado, coniferas, eucaliptus } \\
\text { 2.4.4 mosaico de pastos y espacios naturales } \\
\text { 3.1.2.1 bosque natural fragmentado con arbustos y matorrales } \\
\text { 2.4.2 mosaico de pastos y cultivos } \\
\text { 3.1.1 bosque natural denso } \\
\text { 3.1.2.2 bosque natural fragmentado }\end{array}$ & $\begin{array}{l}\text { Flujos de lodo en invierno } \\
\text { Residuos fecales de la ganaderia } \\
\text { Sedimentación por erosion del suelo }\end{array}$ \\
\hline Andino & $\begin{array}{l}\text { 3.1.2.1 bosque natural fragmentado con arbustos y matorrales } \\
\text { 3.1.1 bosque natural denso } \\
\text { 2.4.4 mosaico de pastos y espacios naturales } \\
\text { 2.4.2 mosaico de pastos y cultivos }\end{array}$ & $\begin{array}{l}\text { Aporte de agroquimicos } \\
\text { Residuos fecales de la ganaderia } \\
\text { flujos de lodo en invierno }\end{array}$ \\
\hline Subandino & \begin{tabular}{|l} 
2.2.5 café \\
2.2.4 platano y banano \\
2.4.3 mosaico de pastos, cultivos y espacios naturales \\
3.1.2.2 bosque natural fragmentado \\
2.4.2 mosaico de pastos y cultivos \\
\end{tabular} & $\begin{array}{l}\text { Lixiviados de la produción de café } \\
\text { Sedimentación por erosion del suelo, } \\
\text { Aportede agroquímicos } \\
\text { flujos de lodo en invierno }\end{array}$ \\
\hline Subandino & $\begin{array}{l}\text { 2.2.4 platano y banano } \\
\text { 2.2.2 caña de azúcar } \\
\text { 1.2.1 zonas industriales o comerciales } \\
\text { 1.4.3 finca recreo parcelaciones } \\
\text { 3.1.2.2 bosque natural fragmentado } \\
\text { 2.3.2 pastos arbolados } \\
\text { 2.2.5 café }\end{array}$ & $\begin{array}{l}\text { Aportede agroquímicos } \\
\text { lixiviados de la produción de café } \\
\text { Sedimentación por erosion del suelo, }\end{array}$ \\
\hline Andino y Subandino & $\begin{array}{l}\text { 3.1.2.2 bosque natural fragmentado } \\
\text { 3.1.5.1 bosque plantado, coniferas, eucaliptus } \\
\text { 1.4.3 finca recreo parcelaciones } \\
\text { 2.4.4 mosaico de pastos y espacios naturales } \\
\text { 2.2.5 café }\end{array}$ & $\begin{array}{l}\text { Residuos fecales de la ganaderia } \\
\text { Aportede agroquímicos }\end{array}$ \\
\hline Andino y Subandino & $\begin{array}{l}\text { Asume los usos del suelo en las areas de captación de } \\
\text { las cuencas de Campoalegritoy de la cuenca del Rio Otún }\end{array}$ & $\begin{array}{l}\text { Asume los problemas de los rios } \\
\text { Campoalegrito y el Otún } \\
\text { (AGUA EN BLOQUE) }\end{array}$ \\
\hline $\begin{array}{l}\text { Andino y Subandino } \\
\text { subandino }\end{array}$ & $\begin{array}{l}\text { 3.1.2.1 bosque natural fragmentado con arbustos y matorrales } \\
\text { 3.1.5.1 bosque plantado, coniferas, eucaliptus } \\
\text { 3.1.2.2 bosque natural fragmentado } \\
\text { 1.4.3 finca recreo parcelaciones } \\
\text { 2.4.4 mosaico de pastos y espacios naturales } \\
\text { 2.2.5 café } \\
\text { 3.1.2.2 bosque natural fragmentado } \\
\text { 2.2.2 caña de azúcar } \\
\text { 2.3.2 pastos arbolados }\end{array}$ & $\begin{array}{l}\text { Disminución de caudales en verano } \\
\text { flujos de lodo en invierno } \\
\text { Residuos fecales de la ganaderia } \\
\text { Aporte de agroquímicos } \\
\text { Aporte de agroquímicos }\end{array}$ \\
\hline subandino & \begin{tabular}{|l|} 
2.3.2 pastos arbolados \\
2.2.4 platano y banano \\
2.4.2 mosaico de pastos y cultivos
\end{tabular} & Aporte de agroquímicos \\
\hline Andino y Subandino & $\begin{array}{l}\text { 3.1.2.2 bosque natural fragmentado } \\
\text { 3.1.5.1 bosque plantado, coníferas, eucaliptus } \\
\text { 2.4.3 mosaico de pastos, cultivos y espacios naturales } \\
\text { 2.2.5 café } \\
\text { 3.1.1 bosque natural denso } \\
\text { 1.4.3 finca recreo parcelaciones } \\
\text { 2.2.4 platano y banano } \\
\end{array}$ & $\begin{array}{l}\text { Lixiviados de la produción de café } \\
\text { Sedimentación por erosion del suelo, } \\
\text { Disminución de caudales en verano } \\
\text { flujos de lodo en invierno }\end{array}$ \\
\hline Andino y Subandino & $\begin{array}{l}\text { 2.2.5 café } \\
\text { 2.2.4 platano y banano } \\
\text { 3.1.2.1 bosque natural fragmentado con arbustos y matorrales } \\
\text { 3.1.1 bosque natural denso } \\
\text { 2.4.4 mosaico de pastos y espacios naturales } \\
2.2 .5 \text { café }\end{array}$ & $\begin{array}{l}\text { Sedimentación por erosion del suelo, } \\
\text { Residuos fecales de la ganaderia } \\
\text { lixiviados de la produción de café } \\
\text { Aportede agroquímicos } \\
\text { Disminución de caudales en verano } \\
\text { flujos de lodo en invierno }\end{array}$ \\
\hline
\end{tabular}


«una tendencia creciente de los sistemas de acueducto, es el aumento de la carga sólida derivada de la erosión superficial de suelos y representada en la turbiedad y en el aumento de la carga contaminante».

En términos ecológicos, el Estudio Hídrico Nacional de 2005 ha determinado que en los municipios estudiados se presenta un índice de escasez hídrica13 (ver cuadro 2), con niveles que varían entre muy alto (demanda superior al $50 \%$ de la oferta hídrica local) y medio alto, es decir demanda apreciable entre 21 y $50 \%$ de la oferta hídrica local.

Los ecosistemas andino y subandino corresponden a conjuntos de selvas residuales fragmentadas en la cordillera conectados por corredores ecológicos naturales dispuestos por las condiciones del relieve (cañones, valles o rondas de los ríos) establecidos entre los 1200 m.s.n.m. y 3500 m.s.n.m. (ver fig. 3). En su interior, estos ecosistemas mantienen niveles de humedad entre $70 \%$ y $90 \%$, lo que permite contener un abundante recurso hídrico en estados de evapotranspiración y líquido superficial y subsuperficial. Su mecanismo de retención deriva de las precipitaciones orográficas en la cordillera, precipitación retenida en un primer momento por medio de las condiciones de estratificación arbórea de cada ecosistema, y de las posibilidades de confinamiento de agua transferida al suelo, el cual está conformado por depósitos de coluviones volcánicos altamente tolerables a la infiltración y saturación de agua.

En términos ecológicos, la selva andina se localiza en altitudes entre 2350 y 3750 m.s.n.m., y presenta una estructura y composición espacial compleja dada la riqueza de especies distribuidas tanto en su estratificación vertical como horizontal predeterminada por factores orográficos que permiten su expansión y por las actividades agropecuarias dadas en sus bordes. Se caracteriza también por sus condiciones de niebla y nubosidad permanente, aspecto determinante en el crecimiento de la flora, la cual desarrolla adaptaciones especiales en el tamaño de sus hojas. La estratificación de la selva andina no supera los 20 metros de altitud y con presencia de helechos arbóreos y palmas.

En el caso del ecosistema subandino, este se enmarca en la zona caficultora de los Andes entre los 1500 y 2000 m.s.n.m.; corresponde a bosques húmedos con presencia de robledales con gran amplitud altitudinal de 20 a 35 metros de altura, con estratos emergentes discontinuos de dos a tres estratos. Al mismo tiempo presenta abundancia de palmas, epífitas y helechos arbóreos y una rápida capacidad de sucesión ecológica en relación con el ecosistema andino.

Los dos ecosistemas cumplen funciones de retención de humedad y recarga hídrica de las cuencas de los ríos Chinchiná, Campoalegre, Otún, Consota, Barbas, Quindío, Espejo y Santo Domingo. Por lo tanto, los remanentes andinos y

13 Entendida como la relación porcentual demanda-oferta, ejercida por las actividades sociales y económicas en su conjunto para su uso y aprovechamiento, con la oferta hídrica disponible o neta (IDEAM, 2008). 
La sostenibilidad hídrica de la dispersión urbana en los Andes centrales colombianos: el eje cafetero

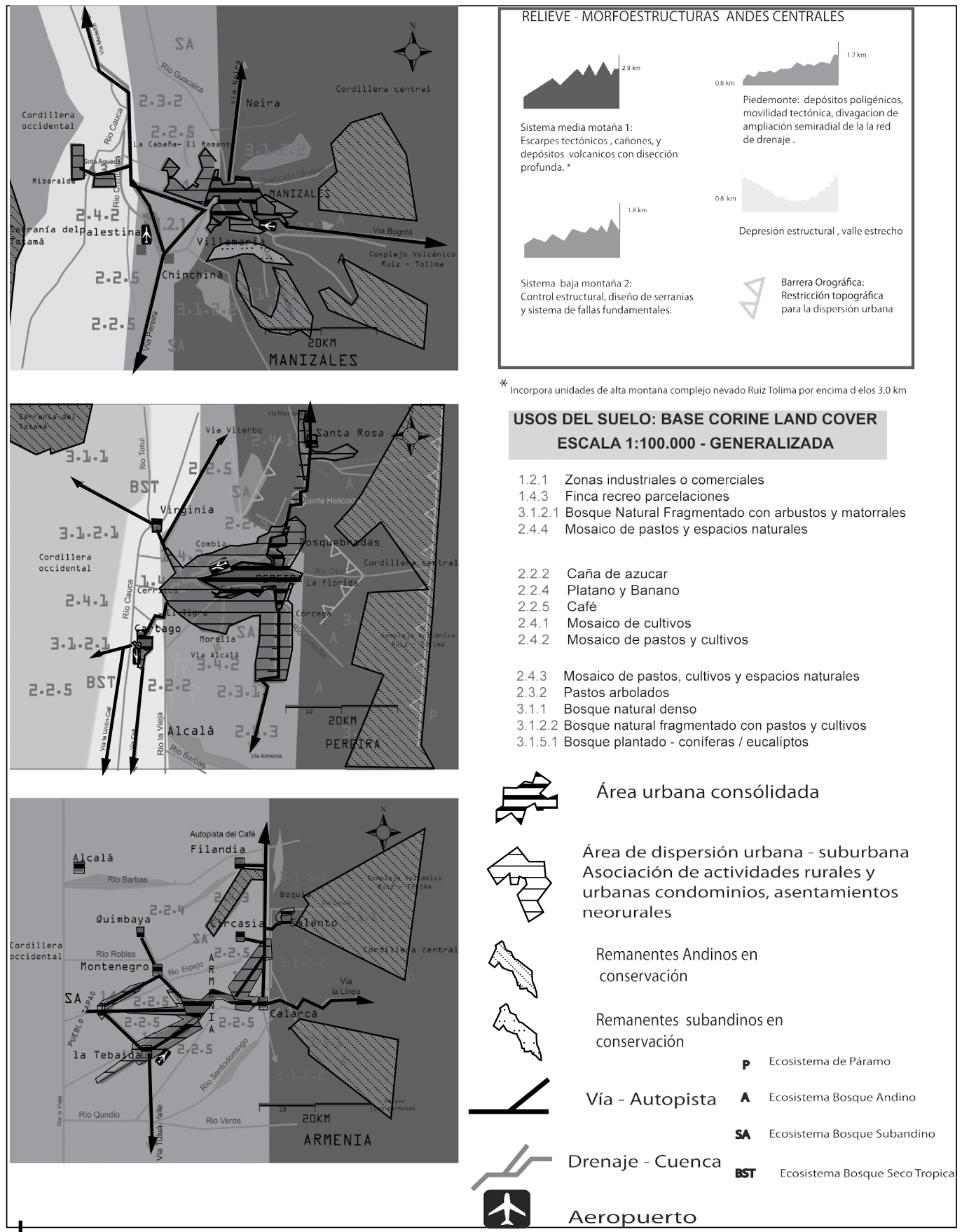

Figura 3 - Localización de ecosistemas andinos, subandinos y usos del suelo

Juan Leonardo González 
subandinos se localizan próximos a los sistemas urbanos o dentro del proceso de dispersión urbana.

Según la clasificación CORINE LAND COVER (IGAC, 2007), los dos ecosistemas se clasifican como bosque natural denso y bosque natural fragmentado, clasificación que en las categorías morfológicas propuestas por Riiter (2000: 34), en el caso andino sobresalen las formas de bosque perforado, bosque de transición, al tiempo que en el ecosistema subandino sobresale la presencia de bosque borde y bosque parche.

La presencia de estas formas forestales y su clasificación de uso explica en sí la acción histórica de las actividades humanas en cada uno. Esto significa que los remanentes andinos presentan coberturas forestales más amplias que el subandino y menos intervenidas. Estos estados de conservación e intervención tienen que ver con las posibilidades de acceso a estos espacios, las condiciones abruptas del relieve, una tenencia de la tierra tendiente al latifundio y un poblamiento rural incipiente en comparación con los procesos de poblamiento campesino cafetero de minifundio y de la simbiosis entre cafetales y bosques que elaboran en sí el paisaje cultural cafetero al interior del ecosistema subandino.

A continuación, el estudio identificó tres factores que determinan la oferta hídrica inicial de los ecosistemas antes de ingresar a las captaciones: (a) el impacto de las actividades agropecuarias, (b) el proceso erosivo y (c) la ruptura de los corredores ecológicos entre los remanentes andinos y subandinos.

El primer factor plantea que, para el caso de los bosques andinos, las cuencas de abastecimiento lechero tienden a incrementar y tecnificar sus áreas de producción en las vertientes andinas, hecho evidente en las cuencas altas de los ríos Chinchiná (sector de la microcuenca de la quebrada Chupaderos), cuenca de la quebrada Campoalegrito (vía Santa Rosa-Termales), cuenca del río Otún (sector de la Florida y la Pastora). Los productores, generalmente campesinos con tierras propias o bajo figuras de arrendamiento de tierras, se ven obligados a utilizar fertilizantes como la urea para mantener sus cotas de producción de leche en las que su precio está fijado en parte por la oferta de producción local14. El sentido de propiedad de la tierra es un aspecto importante ya que esto limita o estimula la ampliación de las áreas para pastos por medio de la deforestación15.

Por lo tanto, el grado de pertenencia en las relaciones sociedad naturaleza del campesinado, la propiedad, el conocimiento del bosque, sus limitadas alternativas de producción económica y de ausencia de infraestructuras viales óptimas para su comunicación son factores determinantes en la alteración de la calidad del agua antes de ser captada, con caudales que presentan coliformes.

14 Trabajo de campo etnográfico con campesinado de las cuencas altas de la quebrada California y río claro en Villamaría.

15 La subdirección de gestión ambiental sectorial en el tercer trimestre de 2009 reportó 243 denuncias ambientales de las cuales 132 corresponden a hechos de deforestación y 52 a deterioro de fuentes hídricas. Igualmente, en el informe del cuarto trimestre presenta 140 denuncias de las cuales 81 corresponden a deterioro de coberturas de bosques y 34 de cuerpos de agua (Informes trimestrales, subdirección de gestión Ambiental CARDER, 2009). 
En el caso de las selvas subandinas, la concentración poblacional desarrollada por el poblamiento rural y urbano a partir de la economía cafetera ha incidido durante casi 140 años en la transformación de los reductos forestales en asociaciones de cafetales con bosques de guadua y elementos subandinos que aún se integran por la presencia de diferentes corredores ecológicos impactados por obras de infraestructura como la autopista del Café.

$\mathrm{Al}$ igual que los bosques andinos la tenencia de la tierra es fundamental, pero en este caso la fragmentación de la propiedad a partir de la misma demanda de poblamiento urbano y rural hace que el agroecosistema cafetero tienda a desaparecer para abrir paso a usos de suelos industriales, residenciales y de servicios. Este hecho, evidente en cuencas de los ríos Otún16 Espejo, Barbas, Santo Domingo y Quindío, incorpora un nuevo tipo de vertimiento en las cuencas que se suman a los vertimientos de aguas mieles de la producción cafetera y que incrementan el aporte de materia orgánica en los caudales a ser captados.

Un segundo factor se enfoca en la dinámica de los procesos erosivos en los alrededores de los remanentes forestales andinos y subandinos. En sí independiente de los procesos naturales de movimientos en masa, los cuales definen el perfil de equilibrio de las vertientes andinas, el trabajo del pastoreo, la implementación de pastos foráneos para ganadería y las malas prácticas en la rotación de los suelos principalmente en contextos cafeteros, aceleran los procesos de erosión superficial que según el informe «afectan las áreas de captación por medio de la precedencia de carga solida por los aportes de sedimentación y turbiedad del agua» (PDA Quindío, 2008: 22).

El tercer factor tiene que ver con la espacialidad de las actividades ganaderas y cafetaleras que incide en la reducción de conexiones entre los ecosistemas andinos y subandinos debidos al deterioro de los corredores ecológicos existentes. De esta forma, su desaparición o afectación reduce tanto las coberturas boscosas y las capacidades de transferir caudales para ampliar los sistemas de acueducto, al punto de ser necesarios la proyección, transporte y venta de agua en bloque entre las ESP. Esta situación tiende a incrementar los costos de operación y administrativos del suministro de agua.

En otro sentido, la afectación de los corredores implica una reducción de las posibilidades de suministro continuo de agua a los sistemas de acueducto al punto que el sistema natural no responda a las demandas de agua en temporadas secas ${ }^{17}$

16 Otra causa por la cual los prestadores del servicio de acueducto en la zona rural buscan otras fuentes hídricas abastecedoras, es la calidad del agua captada, muchas veces afectada por los vertimientos de aguas residuales domésticas o agropecuarias (principalmente asociadas al beneficio del café o la producción avícola, porcina y/o ganadera), como es el caso del Corregimiento de Combia Alta en algunas zonas, donde la calidad del agua es afectada por altos contenidos de sedimentos, producto de procesos erosivos asociados tanto a actividades antrópicas como a procesos naturales propios de suelos con fuertes pendientes y con características de inestabilidad (PDA Quindío, 2008: 23).

17 El caso del Corregimiento de Combia Alta, donde existen zonas que se caracterizan por su alta producción hídrica, al tener influencia directa con el Parque Natural Regional Serranía Alto del Nudo, presenta afectaciones en sus coberturas boscosas por presencia de actividades agropecuarias y procesos erosivos de importantes proporciones, por coincidir con relieves de fuertes pendientes, 
en contraste con las temporadas turísticas. Este caso es factible en lugares como Cerritos, Combia, Boquía, Córcega 18 y la Tebaida, Pueblo Tapao en Risaralda y Quindío19 donde los nuevos usos del suelo urbano intervienen los trayectos de los corredores a partir de las modificaciones de taludes, nivelaciones y excavaciones en la ampliación de espacios planos para urbanizar.

De otro lado, el deterioro de los corredores, los procesos erosivos y las deforestaciones puntuales como en los sitios de la Cabaña, Boquía y Córcega vulneran la capacidad de funcionamiento de los sistemas de acueducto frente a una temporada invernal. En este aspecto, la recarga hídrica que se transfiere principalmente por los afluentes, no tiene la posibilidad de retención hídrica debido a la ausencia de coberturas andinas y subandinas, generando así las condiciones de desarrollo de flujos de lodo que afectan las áreas de captación20.

Ante esta situación, es pertinente resaltar que el Plan Ambiental Regional PGAR 2003-2012 promueve estrategias de conservación (los corredores de las cuencas del Quindío, Barbas y Consota) considerando la promoción de corredores no solo como una alternativa para la estabilidad hidrológica sino como un elemento de enorme valor económico en los proyectos turísticos e inmobiliarios21.

Lamentablemente, al no existir una coherencia en el desarrollo de agendas conjuntas para ordenar el proceso de dispersión urbana entre los municipios, la cohesión ecológica establecida en una escala regional $(1: 400.000)$ y en la que se encadenan ecosistemas de páramos, andinos, subandinos y bosques seco tropicales, tiende a reducirse.

que no solo afectan las viviendas, instituciones educativas, infraestructuras viales y productivas, sino también, los diferentes componentes de los sistemas de suministro, vitales para el suministro de agua para el consumo humano de una población que para este caso, representa aproximadamente el $13 \%$ de la población rural total (Agudelo \& Orozco, 2009: 107).

18 Esta situación se viene presentando de manera preocupante en el Corregimiento de Tribunas, entre otros, donde la intervención urbanística, por planificación inadecuada, y la proliferación de proyectos campestres y de infraestructura que no cuentan con medidas conjuntas de seguimiento y control eficientes y permanentes, afectan el entorno natural y en consecuencia, la calidad del agua de tres acueductos rurales (Asociación de Usuarios del Acueducto Cantamonos, Asociación de Usuarios del Acueducto Caracol - El Rocío y Asociación de Usuarios de la Empresa de Servicios Públicos Tribunas-Córcega) que abastecen aproximadamente el $15 \%$ de la población rural total municipal. (Agudelo \& Orozco, 2009: 108).

19 Noticia temporada seca en Quindío.

20 Noticia vulnerabilidad de los sistemas de acueducto.

21 La agenda para el desarrollo de la ecorregión eje cafetero 2007-2009 ha establecido como meta el potenciamiento de actividades productivas sostenibles aprovechando la plataforma de los recursos naturales de agua, suelos y los sectores sociales culturales que lo conforman. Al contrario de lo expuesto, los desarrollos infraestructurales y la promoción de cadenas productivas y clúster de mercados ecoturísticos, ganaderos y de bosques comerciales ejercen una presión negativa en la sostenibilidad ecológica de los suelos por medio del cambio de vocación de estos (transformación del paisaje cultural cafetero por escenarios inmobiliarios residenciales, turísticos, agroindustriales) y de la biodiversidad, situaciones concretas dadas a lo largo de la autopista del café. 


\section{LA OFERTA HÍDRICA Y LA EFICIENCIA DE LAS ESP}

La eficiencia en la prestación del servicio de acueducto depende fundamentalmente de dos factores. Uno, es la disponibilidad del recurso hídrico, ligado principalmente a las condiciones topográficas, geomorfológicas e hidrológicas de las cuencas que abastecen los sistemas, así como las políticas y programas formulados y ejecutados por las autoridades competentes para su efectiva conservación y aprovechamiento. El otro factor es la eficiencia operativa, administrativa y financiera de las ESP que prestan el servicio en la zona, ya que sin esto no es posible garantizar un grado de aceptabilidad de los indicadores de calidad operativa del sistema y por ende restringiría el crecimiento urbano de una comunidad que demanda altos estándares de calidad para su desarrollo.

En las áreas de estudio operan diez ESP de más de 2500 suscriptores y una de menos de 2500 suscriptores, oficialmente registradas ante la Superintendencia de Servicios Públicos. Cabe señalar que, para el caso del sistema urbano de Pereira, existen 54 asociaciones de usuarios de acueductos y un número no determinado de asociaciones para los casos de Manizales y Armenia cuyos inicios se deben a los apoyos técnicos provistos por la Federación Nacional de Cafeteros durante más de 30 años y que no reportan registros ante el SUI, en vista que su estructura operativa y técnica son deficientes (ver fig. 4). De todos modos, estas pequeñas asociaciones que prestan cobertura en escalas veredales cubren escenarios puntuales donde las ESP registradas no operan.

Como generalidad en las áreas de dispersión urbana, según la revisión de los PDA del Quindío, Risaralda y Caldas aprobados en 2008 y 2009 se identificaron deficiencias en la prestación de los servicio de acueducto que tienen que ver con: tarifas mal aplicadas, catastros de usuarios desactualizados, mala aplicación o inexistencia de los fondos de solidaridad y redistribución del ingreso, desequilibrio entre los subsidios y las contribuciones, deficiencias en el cargue de la Información al Sistema Único de Información (SUI), software y hardware incompletos y desactualizados, desconocimiento en el manejo de los indicadores comerciales, administrativos, financieros y técnicos, desconocimiento en la separación de las contabilidades, por poca difusión o socialización de los resultados de estudios de tarifas, usuarios, estratificación, mal manejo de las PQRS (peticiones, quejas y reclamos) y desconocimiento de los aspectos financieros y administrativos.

Lo anterior sería un panorama de la prestación del servicio y por ende de oferta social hídrica de todos los prestadores de los servicios de acueducto registrados y no registrados ante el SUI.

El cuadro 2 presenta las diferentes ESP registradas que pueden acceder a programas de financiamiento, participación y de planeación conjunta en los propósitos de ampliación y mejoramiento formulados en los diferentes PDA departamentales. Al ser evaluados aspectos como tendencia de crecimiento, cobertura de medición, calidad del agua, sistematización de suscriptores identificados para las ESP Aguas de Manizales (2009), Aquamaná (2009), Empocabal (2007), Aguas de Pereira, Serviciudad (2008), EmcartaGO (2007), Empocaldas (Contraloría Municipal de 


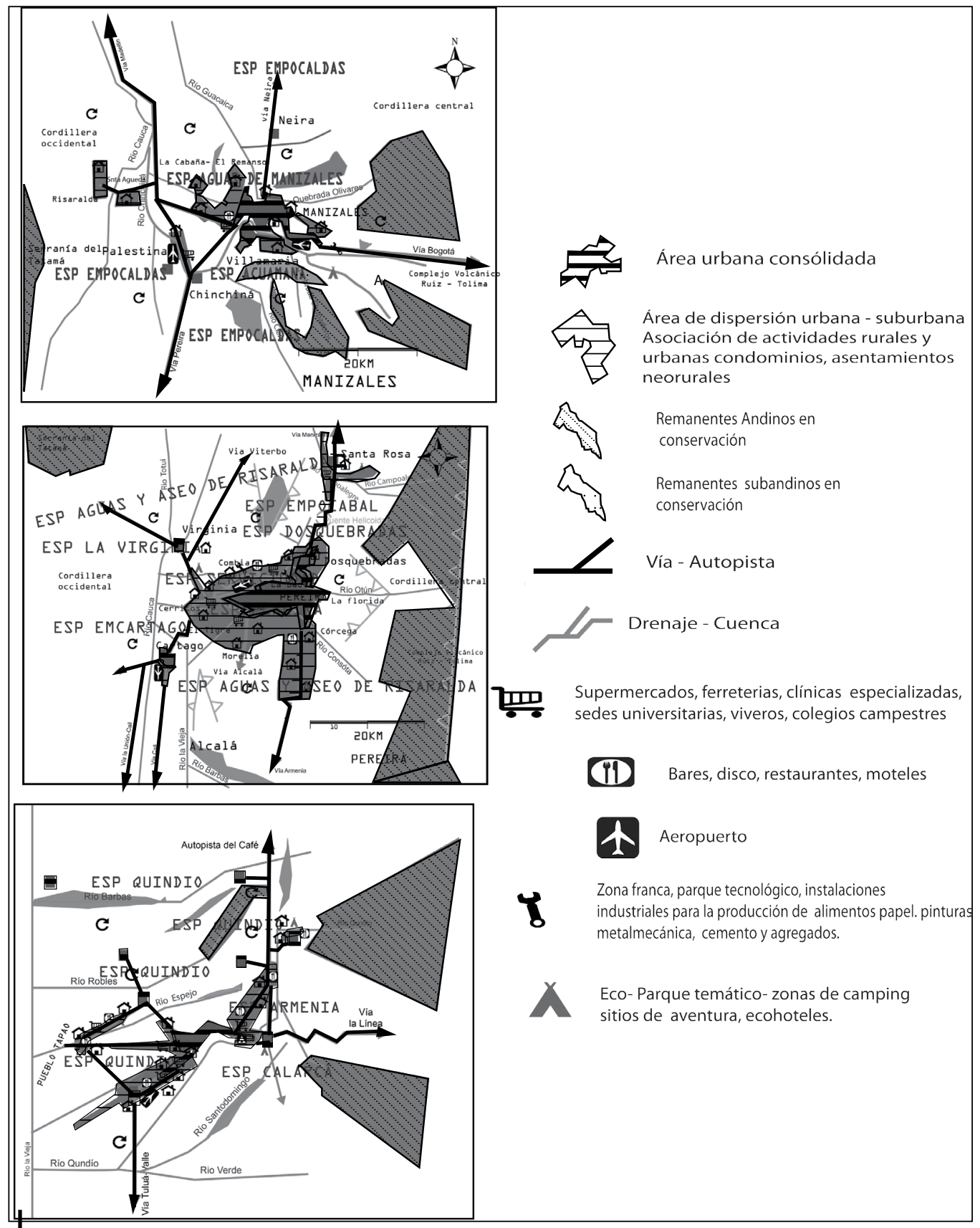

Figura 4 - Presencia de las ESP registradas ante el SUI, y pequeñas asociaciones de usuarios de sistemas de acueductos

Juan Leonardo González 
Caldas 2009, ESP 2008), ESP Pereira (2009) y ESP Armenia (2007), , los resultados demostraron que a pesar de los problemas presentes en las ESP, la Superintendencia de Servicios Públicos ha certificado con niveles bajos de riesgo (IFA) a las ESP del área de estudio, lo cual les permite seguir operando.

\section{1. Adjudicación a las ESP de caudales por las autoridades ambientales, mayores que los caudales mínimos de las fuentes}

Este caso se presenta en Aguas de Manizales S.A. (E.S.P. para las fuentes Blanco, Cajones, Chinchiná, La Arenosa, La María, Olivares y Pinares), en Empresas Públicas de Armenia EPA (E.S.P. para la fuente Río Quindío), en la Empresa Multipropósito de Calarcá S.A. (E.S.P. para la fuente San Rafael, Naranjal y El Salado) y en Emcartago S.A. (E.S.P. para la fuente Río La Vieja). Esta situación no permite garantizar el abastecimiento en épocas de verano intenso. Más grave aún con el conocimiento y la responsabilidad que les compete a las Autoridades ambientales, no se tiene definida una política clara en el otorgamiento de caudales de una fuente que considere las condiciones hidrológicas de cada cuenca para que, de esta manera, se garantice el caudal mínimo ecológico.

\section{2. Renovación de las concesiones de las fuentes ante la autoridad ambiental}

Se hace notorio que empresas como Aquamaná E.S.P. y Emcartago S.A. E.S.P. no presentan en sus reportes la información correspondiente a las concesiones otorgadas por la Autoridad Ambiental. Asimismo, Empocabal y Empresa de Servicios Públicos de La Virginia E.S.P., en sus informes de gestión presentan las concesiones con términos vencidos y no se reportan datos acerca de su renovación.

\section{3. Inconsistencia de los registros de consumos}

Para el año 2007, en Aguas de Manizales E.S.P., se contaba con 85285 usuarios, un Índice de Agua No Contabilizada promedio IANC de 26,9\% y un porcentaje de micromedición de $97,91 \%$. Estos valores no presentan consistencia ya que así, alrededor de 1782 usuarios no contarían con micromedición. Teniendo un caudal promedio de salida de las 3 Plantas de Tratamiento de Agua Potable PTAP de $2719915 \mathrm{~m}^{3} / \mathrm{mes}$, se tiene un volumen facturado promedio de $1988258 \mathrm{~m}^{3} /$ mes. Los usuarios con un consumo promedio de $9,52 \mathrm{~m}^{3} /$ usuario*mes consumirían $^{*}$ $16965 \mathrm{~m}^{3} / \mathrm{mes}$, los cuales representan el $0,9 \%$ del total facturado. Con los valores reportados, el consumo promedio sería de $23,3 \mathrm{~m}^{3} /$ usuario*mes, el volumen que consumirían los usuarios sin micromedición sería $41521 \mathrm{~m}^{3} / \mathrm{mes}$, el volumen facturado sería de $811913 \mathrm{~m}^{3} / \mathrm{mes}$, siendo este valor inconsistente con el calculado con las pérdidas reportadas. Así las pérdidas de agua serían del orden del 70 \%. 
En la EPA, los consumos reportados son del orden de $16001214 \mathrm{~m}^{3} / \mathrm{año}$, en discordancia con lo que se reporta como facturado que asciende a 20023282 $\mathrm{m}^{3}$ /año. Asimismo, la cobertura en micromedición presenta valores muy bajos y variables año a año, lo cual permite suponer que el IANC debe ser alto. Sin embargo la empresa reporta un IANC del 19,02 \%. La información reportada al SUI por Empocabal presenta inconsistencia en cuanto al volumen de agua consumido para el año 2006, el cual difiere en magnitud considerable respecto a los demás años. Se tiene para el año 2007 un consumo aproximado de 2,8 millones de $\mathrm{m}^{3}$.

\section{4. Inconsistencia con la cobertura en micromedición}

Empocabal reporta un valor superior al 100 \% en cobertura de micromedición, valor que en la práctica es físicamente imposible si se tiene en cuenta que a lo sumo se podría tener una cobertura en micromedición del $100 \%$.

\section{5. Problemas con la calidad del agua suministrada}

Aguas de Pereira, en cuanto a la calidad del agua suministrada a los usuarios, reporta un IRCA del 6,2 \% con bajos porcentajes de aceptabilidad en varios parámetros físicos, químicos y microbiológicos de acuerdo con las muestras evaluadas por las autoridades sanitarias observando problemas en la calidad del agua que se entrega a los usuarios. Empocabal presenta un índice de calidad de agua del 86,01\%, el cual nos muestra que el agua suministrada no posee las condiciones mínimas para que sea apta para el consumo humano. Los informes sugieren realizar un plan de acción tendiente a optimizar la calidad del agua y del servicio de manera óptima. En la Empresa de Servicios Públicos de La Virginia se tiene un índice de aceptabilidad del 50 \%, lo cual evidencia la deficiencia en la calidad del agua suministrada. Aquí se muestra que el número y la frecuencia de los muestreos no cumplen con la normatividad. Las muestras se toman al interior de los domicilios. Además, se evidencian fallas generales en los procesos de desinfección. Para Serviciudad de Dosquebradas, se presentan problemas en cuanto a la calidad del agua, reportando un porcentaje de aceptabilidad de $0 \%$. En la toma de muestras se ha evidenciado incumplimiento en parámetros físicos, químicos y microbiológicos. También el número y frecuencia de los muestreos no cumple con lo estipulado en la ley, los sitios de muestreo no han sido concertados con la autoridad sanitaria y se presentan fallas en los procesos de potabilización. Para los sistemas de Chinchiná y Palestina que atiende Empocaldas, el IRCA reporta un valor de $6 \%$ en Chinchiná, ubicándolo en nivel de riesgo bajo y de $22,4 \%$ en Palestina quedando en niveles de riesgo medio por el manejo inapropiado de las propiedades físicas, químicas y microbiológicas que debe tener el agua para ser apta al consumo. Para la E.S.P. Calarca, el IRCA reportado muestra que el agua suministrada se considera apta para consumo humano. Pero ya que las muestras son tomadas al interior de los domicilios, a la empresa se le 
sugiere coordinar con la autoridad sanitaria y de salud la concertación de puntos de muestreo acorde con la ley.

\section{DISCUSIÓN FINAL}

La dispersión urbana que en la actualidad se proyecta desde los sistemas urbanos principales del eje cafetero como Manizales, Pereira y Armenia es un fenómeno que, dada su progresión espacial, se extiende hacia los municipios que gravitan en cada uno de estos sistemas principales. A medida que se extiende la red urbana entre los municipios estudiados se define una serie de escenarios urbanos en formación, desagrupados, donde se localizan diferentes tendencias de usos como el residencial, el comercial, el industrial y el de servicios. Estas localizaciones se convierten finalmente en nodos de crecimiento urbano locales sobre los cuales se proyectarían a futuro otros procesos de crecimiento y desarrollo urbano.

Previendo esta tendencia de incremento de áreas urbanas en el eje cafetero, se plantea por parte del autor la preocupación acerca de las condiciones de dotación y calidad de los acueductos demandados por estas nuevas distribuciones urbanas, teniendo en cuenta las capacidades de los bosques andinos y subandinos para confinar y regular el suministro natural de caudales, el impacto de la transformación de los usos del suelo en los contextos de captación de los acueductos y finalmente, la forma cómo las ESP reconocidas por la CRA y por la Superintendencia de Servicios Públicos a nivel regional en el eje cafetero, vienen realizando su ejercicio de suministro de acueducto con calidad.

En vista de lo anterior, el artículo propone que la oferta hídrica es un aspecto que reposa no solo en la evaluación de las condiciones biofísicas, o de las condiciones ecológicas de la vertiente andina, sino que además incorpora dinámicas sociales referidas al dimensionamiento de los conflictos dados en el cambio de uso del suelo. Por un lado, esta situación incide en gran forma sobre el proceso ecológico y, por otro, en las condiciones técnico-operacionales de las ESP, aspecto determinado por las características de calidad establecidas en cada una de estas.

Por lo tanto, las características de la oferta hídrica dispuestas en el contexto de dispersión urbana en el eje cafetero están mediadas ante todo en la definición de la magnitud del hecho urbano establecido. No se evalúan por una situación de planeación conjunta entre las municipalidades, sino al contrario por situaciones relacionadas con la crisis social de la ruralidad, la especulación orientada por intereses particulares, los conflictos del uso del suelo en los contextos de captación, y las irregularidades en el suministro de agua con calidad para consumo por parte de las ESP.

Los resultados de la investigación establecen una serie de situaciones que comprometen la eficiencia de esta oferta hídrica al momento de ser explicadas desde las acciones sociales y físicas. Un primer resultado permite ver que la magnitud de la dispersión urbana es un hecho no planificado en un contexto de ordenamiento territorial conjunto entre los municipios donde se da este fenómeno. 
Al no existir tal planeación, la emergencia de nuevos enclaves urbanos conduce a que su demanda se soporte en lugares donde las estructuras de acueductos no están previstas para un desarrollo urbano sino para un contexto de demandas rurales. En los casos en los cuales las coberturas provistas por las ESP están en proyección, su eficiencia pone en entredicho la calidad del agua para consumo. En otras partes, son evidentes las irregularidades en las lecturas de consumos al no tener registros exactos, lo que demuestra la precariedad de sus estructuras frente a eventos de invierno o periodos secos máximos. Es decir, la progresión dispersa del proceso urbano incrementa espacialmente los problemas de eficiencia de la cobertura, vistos en los informes de las ESP.

Un segundo resultado establece que la transformación del uso del suelo dado por la inserción de las nuevas actividades urbanas a nivel local revierte e incrementa la problemática presente en la ruralidad de las áreas de estudio. La promoción de nuevos escenarios urbanos irrumpe en las estructuras del campesinado local y regional al momento de cambiar los usos del suelo. Con esto se quiere señalar que el deterioro de las actividades rurales recalifica la relación con el manejo del suelo en sus formas de conservación y de manejo alternativo entre bosques que cumplen funciones de regulación y usos agrícolas, llevando a que las iniciativas históricas de conocimiento y conservación en función de la oferta hídrica local tiendan a desaparecer. Por lo tanto, las nuevas necesidades de agua y de oferta hídrica se transfieren hacia ecosistemas no necesariamente localizados en estos lugares sino en escenarios distantes enclavados en las vertientes de la cordillera central.

La oferta física y ecológica estudiada tiende entonces a depender de una serie de remanentes andinos y subandinos con diferentes situaciones de intervención por prácticas rurales, las cuales inciden en el detrimento de las áreas de bosques, en la irrupción de los corredores ecológicos vitales para la regulación hídrica y en la calidad del agua al momento de ser captada, calidad que viene afectada desde el primer momento por el aporte de materia orgánica (coliformes) y fertilizantes presentes en las actividades ganaderas de las vertientes andinas.

En línea con lo anterior, un tercer resultado ha determinado que existe una serie de ESP reconocidas, registradas y certificadas, las cuales presentan inconsistencias, desconocimiento de sus caudales otorgados por las autoridades ambientales, deficiencias en su infraestructura, en sus condiciones de potabilización y una precaria relación entre estas y las Corporaciones Autónomas Regionales en la elaboración y ejecución de agendas conjuntas encaminadas al uso, manejo y conservación de los remanentes y corredores andinos y subandinos que sustenta la oferta de agua inicial.

En este sentido es claro que en el momento existe omisión y ausencia de participación de las ESP, tanto en el ordenamiento y planeación de los ecosistemas estratégicos de donde se proveen, como de su voluntad para incidir sobre los problemas sociales y ecológicos desarrollados en la ruralidad donde se localizan sus áreas de captación. Al mismo tiempo, los agentes que promocionan la conversión del uso del suelo rural a urbano y que aprovechan las circunstancias actuales de crisis rural para fomentar el reemplazo de unidades productivas por lotes para nuevos usos residenciales, 
comerciales, industriales y de servicios son totalmente indiferentes a las condiciones actuales que inciden en el detrimento de las condiciones de regulación hídrica en los ecosistemas. Tal comportamiento, ajeno a las realidades sociales y ambientales tanto en sus áreas de operación como en los escenarios de regulación hídrica, obstruye las disposiciones en materia de uso, manejo y conservación del suelo y de biodiversidad establecidos en cada uno de los planos de ordenamiento territorial de los municipios donde se da la dispersión urbana.

Por último, cabe destacar que la oferta hídrica dada en la dispersión urbana del eje cafetero tiende a ser cada vez más frágil en la medida que este fenómeno incrementa su área y su demanda, en la medida que los PDA formulados desde 2008 carecen de evaluaciones acerca de las condiciones socioeconómicas de los lugares estudiados, haciendo ineficiente la proyección de las nuevas infraestructuras en agua y saneamiento. Tales situaciones llevan a pensar como discusión final que la oferta hídrica para el caso de estudio queda en manos de las voluntades políticas locales y regionales a partir de su grado de compromiso social sobre el acato a los mecanismos de planeación desarrollados por los municipios, así como de las tendencias de especulación sobre los usos del suelo para propósitos inmobiliarios y por último del mejoramiento en las condiciones técnico-operacionales de las ESP estudiadas, el cual es un aspecto que depende de su correcta administración y planeación interna y de su grado de vinculación con los propósitos de desarrollo regional y local.

\section{Referencias citadas}

AGUAS DE MANIZALES (ESP), 2009 - Evaluación integral; Bogotá: Superintendencia de Servicios Públicos Domiciliarios (consultado 10/09/2010).

http://www.superservicios.gov.co/home/web/guest/aaa

ACUAMANA (ESP), 2009 - Evaluación integral; Bogotá: Superintendencia de Servicios Públicos Domiciliarios (consultado 11/09/2010).

http://www.superservicios.gov.co/home/web/guest/aaa

ALLEN, A., 2001 - Environmental planning and management of the peri-urban interface in Conference rural. Urban encounters: Management the environment of the periurban interface, London 9-10, November 2001.

http://newruralism.pbworks.com/f/allen.pdf

AGUDELO, I. \& OROZCO, I., 2009 - Diagnóstico acueductos veredales de Pereira; Pereira: Secretaría de Planeación Municipal, Alcaldía de Pereira.

ARMENTERAS, D. \& RODRÍGUEZ, N., 2007 - Monitoreo de los ecosistemas andinos: 19852005: Síntesis; Bogotá DC.: Instituto de Investigaciones de Recursos Biológicos Alexander Von Humboldt.

AVILA, H., 2004 - Lo urbano-rural en el estudio de los procesos territoriales, 19 pp.; México. Documento de consulta Programa de Estudios Regionales CRIM-UNAM. http://www.fidamerica.org/admin/docdescargas/centrodoc/centrodoc_8750.pdf 
BARROS, C.,1999 - «De rural a rururbano: transformaciones territoriales y construcción de lugares al sudoeste del área metropolitana de Buenos Aires. Scripta Nova, Revista electrónica de Geografía y Ciencias Sociales, n. 45 (52); Barcelona, 1 de agosto. (consultado 10/04/2010). http://www.ub.es/geocrit/sn-45-52.htm

BETTINI, V., 1998 - Ecología urbana, 398 pp.; Madrid: editorial TROTTA.

BLAIKIE, P., CANNON,T. \& WISNER, B., 1996 - Vulnerabilidad: El entorno político y económico de los desastres, 374 pp.; Colombia: Tercer Mundo editores. Red de estudios sociales en prevención de desastres en América latina.

CÁMARA COLOMBIANA DE LA CONSTRUCCIÓN, CAMACOL, 2009 - Panorama de la Construcción en Colombia. http://www.fiic.la/fiic_cr/CAMACOL_Panora_constucc FIIC\%20MPDH\%20nov_2010.pdf informe ejecutivo semestral CAMACŌL.

CONTRALORÍA MUNICIPAL DE ARMENIA, 2009 - Estado de los Recursos Naturales, Vigencia 2008. Consultado 12/09/2010: http://contraloriarmenia.gov.co

CONTRALORÍA MUNICIPAL DE CALDAS, 2009 - Informe de gestión EMPOCALDAS.

Consultado 13/10/2010: http://www.contraloriagen.gov.co/

CORPORACIÓN AUTÓNOMA DE RISARALTA, 2009 - Trámite de denuncias ambientales 2009; Subdirección de Gestión Ambiental Sectorial. http://www.carder.gov.co/ principal.php

DEPARTAMENTO ADMINISTRATIVO NACIONAL DE ESTADÍSTICA (DANE), 2010 - Base estadística del 2005 y el censo de proyección de población a 2015.

DEPARTAMENTO ADMINISTRATIVO NACIONAL DE ESTADÍSTICA (DANE), 2012 - Censo poblacional urbano. http://www.dane.gov.co

DURÁN. F., 2004 - Los límites difusos de los territorios periurbanos: una propuesta metodológica para el análisis de su situación socioeconómica y proceso de cambio. In: Sociologías, año 6, n. ${ }^{\circ}$ 11: 28-63; Porto Alegre.

EMPRESA DE OBRAS SANITARIAS DE CALDAS (EMPOCALDAS ESP), 2008 - Evaluación integral; Bogotá: Superintendencia de Servicios Públicos Domiciliarios. Consultado 13/09/2010: http://www.superservicios.gov.co/home/web/guest/aaa

EMPRESA DE SERVICIOS PÚBLICOS DE SANTA ROSA DE CABAL (EMPOCABAL ESP), 2007 - Evaluación integral; Bogotá: Superintendencia de Servicios Públicos Domiciliarios.

Consultado 13/09/2010 : http://www.superservicios.gov.co/home/web/guest/aaa

EMPRESA DE SERVICIOS PÚBLICOS DE DOSQUEBRADAS (SERVICIUDAD ESP), 2008 Evaluación integral; Bogotá: Superintendencia de Servicios Públicos Domiciliarios. http://www.superservicios.gov.co/home/web/guest/aaa

EMPRESA DE ACUEDUCTO Y ALCANTARILLADO DE PEREIRA S.A. E.S.P., 2009 Evaluación integral; Bogotá: Superintendencia de Servicios Públicos Domiciliarios. Consultado15/09/2010: http://www.superservicios.gov.co/home/web/guest/aaa

EMPOCALDAS S.A. ESP., 2008 - Informe de gestión; Caldas: Gobernación de Caldas.

EMPRESAS PÚBLICAS DE ARMENIA, EPA ESP, 2007 - Evaluación integral; Bogotá: Superintendencia de Servicios Públicos Domiciliarios.

Consultado 13/09/2010: http://www.superservicios.gov.co/home/web/guest/aaa

EMPRESAS MUNICIPALES DE CARTAGO (EMCARTAGO S.A. ESP), 2007 - Evaluación integral; Bogotá: Superintendencia de Servicios Públicos Domiciliarios.

http://www.superservicios.gov.co/home/web/guest/inicio

EMPRESA MULTIPROPÓSITO DE CALARCA (ESP), 2008 - Informe ejecutivo de gestión; Bogotá: Superintendencia de Servicios Públicos Domiciliarios. 
La sostenibilidad hídrica de la dispersión urbana en los Andes centrales colombianos: el eje cafetero

Consultado 25/09/2010: http://www.superservicios.gov.co/home/web/guest/aaa FLOREZ, A., 2003 - Colombia: evolución de sus relieves y modelados [cantidad de págs.]; Bogotá: Universidad Nacional de Colombia, Red de Estudios de Espacio y Territorio.

INSTITUTO DE HIDROLOGÍA, METEOROLOGÍA Y ESTUDIOS AMBIENTALES DE COLOMBIA (IDEAM), 2008 - Estudio Nacional del Agua.

Consultado 30/08/2010:

http://www.cambioclimatico.gov.co/documentos/DocRefCambioClimatico/

DocsEspanol/Colombia/Estudio\%20del\%20Agua.\%20IDEAM.pdf

INSTITUTO GEOGRÁFICO AGUSTÍN CODAZZI (IGAC), 2007 - Levantamiento semidetallado de las coberturas terrestres, metodología de clasificación del uso del suelo CORINE LAND COVER, 260 pp.; Bogotá: Imprenta Nacional de Colombia. Departamento de Antioquia. Subdirección de Agrología.

KAZTMAN, R., 2001 - Seducidos y abandonados: el aislamiento social de los pobres urbanos. Revista CEPAL, $\mathbf{n}^{\circ}$ 75: 171-189.

PEDERSEN, P., 2003 - The implications of nacional-level policies on the development of small and intermediate urban centres. In: Integrating rural development and small urban centers: an evolving framework for effective regional and local economic development; Copenhagen: Institute for International Studies march 18-19.

PLAN DEPARTAMENTAL DE AGUA DEL QUINDÍO (PDAQUINDÍO), 2008 - Informe Técnico; Gobernación del Quindío.

http://www.quindio.gov.co/home/docs/items/item_110/

InformePDAQuindio2008-2009.pdf

PLAN DEPARTAMENTAL DE AGUA DE CALDAS (PDACALDAS), 2008 - Informe Técnico; Gobernación de Caldas.

PINTO, H., 2009 - Contexto económico de la actividad edificadora en Caldas. CAMACOL. http://www.camacol.org.co/adminSite/Archivos/ArtPres_20091106055600.pdf

RIITER, K., 2000 - Global-scale patterns of forest fragmentation. Eco. conservation Ecology, 4: 1-22.

TACOLI, C., 1998 - Rural-urban interactions: a guide to the literature. Environmental and urbanization, 10 (1): 147-66. 